\title{
Silica-gentamicin nanohybrids: combating antibiotic resistance, bacterial biofilms, and in vivo toxicity
}

This article was published in the following Dove Press journal: International Journal of Nanomedicine

\begin{abstract}
Dina A Mosselhy, ${ }^{1-3}$ Wei He, ${ }^{4}$ Ulla Hynönen, ${ }^{5}$ Yaping Meng, ${ }^{6}$ Pezhman Mohammadi, ' Airi Palva, ${ }^{5}$ Qingling Feng, ${ }^{7}$ SimoPekka Hannula, ${ }^{2}$ Katrina Nordström,' Markus B Linder'

'Department of Bioproducts and Biosystems, School of Chemical Engineering, Aalto University, Espoo, Finland; ${ }^{2}$ Department of Chemistry and Materials Science, School of Chemical Engineering, Aalto University, Espoo, Finland; ${ }^{3}$ Fish Diseases Department, Microbiological Unit, Animal Health Research Institute, Dokki, Giza I26/8, Egypt; ${ }^{4}$ School of Materials Science and Engineering, University of Science and Technology Beijing, Beijing, People's Republic of China; ${ }^{5}$ Department of Veterinary Biosciences, Division of Veterinary Microbiology and Epidemiology, University of Helsinki, Helsinki, Finland; ${ }^{6}$ State Key Laboratory of Biomembrane and Membrane Biotechnology, Department of Biological Sciences and Biotechnology, Tsinghua University, Beijing, People's Republic of China; ${ }^{7}$ State Key Laboratory of New Ceramics and Fine Processing, School of Materials Science and Engineering, Tsinghua University, Beijing, People's Republic of China
\end{abstract}

\begin{abstract}
Introduction: Antibiotic resistance is a growing concern in health care. Methicillin-resistant Staphylococcus aureus (MRSA), forming biofilms, is a common cause of resistant orthopedic implant infections. Gentamicin is a crucial antibiotic preventing orthopedic infections. Silica-gentamicin $\left(\mathrm{SiO}_{2}-\mathrm{G}\right)$ delivery systems have attracted significant interest in preventing the formation of biofilms. However, compelling scientific evidence addressing their efficacy against planktonic MRSA and MRSA biofilms is still lacking, and their safety has not extensively been studied.
\end{abstract}

Materials and methods: In this work, we have investigated the effects of $\mathrm{SiO}_{2}-\mathrm{G}$ nanohybrids against planktonic MRSA as well as MRSA and Escherichia coli biofilms and then evaluated their toxicity in zebrafish embryos, which are an excellent model for assessing the toxicity of nanotherapeutics.

Results: $\mathrm{SiO}_{2}-\mathrm{G}$ nanohybrids inhibited the growth and killed planktonic MRSA at a minimum concentration of $500 \mu \mathrm{g} / \mathrm{mL}$. $\mathrm{SiO}_{2}-\mathrm{G}$ nanohybrids entirely eradicated $E$. coli cells in biofilms at a minimum concentration of $250 \mu \mathrm{g} / \mathrm{mL}$ and utterly deformed their ultrastructure through the deterioration of bacterial shapes and wrinkling of their cell walls. Zebrafish embryos exposed to $\mathrm{SiO}_{2}-\mathrm{G}$ nanohybrids ( 500 and $1,000 \mu \mathrm{g} / \mathrm{mL}$ ) showed a nonsignificant increase in mortality rates, $13.4 \pm 9.4$ and $15 \% \pm 7.1 \%$, respectively, mainly detected 24 hours post fertilization (hpf). Frequencies of malformations were significantly different from the control group only $24 \mathrm{hpf}$ at the higher exposure concentration.

Conclusion: Collectively, this work provides the first comprehensive in vivo assessment of $\mathrm{SiO}_{2}$-G nanohybrids as a biocompatible drug delivery system and describes the efficacy of $\mathrm{SiO}_{2}-\mathrm{G}$ nanohybrids in combating planktonic MRSA cells and eradicating E. coli biofilms.

Keywords: $\mathrm{SiO}_{2}$, gentamicin, MRSA, antibacterial and antibiofilm effects, nanotoxicity, zebrafish

\section{Introduction}

Antibiotic resistance is a current hot topic and a significant threat to health care. The antibiotic-resistant bacterium, methicillin-resistant Staphylococcus aureus (MRSA), is at the heart of most clinical cases of notorious orthopedic surgery infections. ${ }^{1}$ S. aureus is also a principal etiological agent of device-related infections and can adhere to the implanted orthopedic devices and then colonize their surfaces forming biofilms. ${ }^{2-4}$ Biofilms are aggregates of bacterial cells enclosed in a diffuse polymeric matrix. ${ }^{5-8}$ Biofilm matrix is resistant to the host immune response and antibacterial agents, which has led to the challenge of treating biofilms, ${ }^{2,7,9}$ to the surgical removal of the implanted device to eliminate the infection, ${ }^{4,6}$ and to remarkable morbidity and mortality 
rates of the patients within hospital settings. ${ }^{2}$ Biofilms also form complex pedestal-like structures, water channels, and pores, ${ }^{8}$ making them physiologically and morphologically different from their planktonic counterparts. ${ }^{10-12}$ The different resistance mechanisms of biofilms to antibiotics have been grouped in a previous review ${ }^{7}$ as follows: 1) the slow penetration of antibiotics into the biofilm matrix; 2) the alteration of the chemical microenvironment within the biofilms, antagonizing the action of antibiotics; and 3) the formation of a highly protected spore-like states by the subbacterial populations of biofilms. Concrete data speaking for the sole responsibility of any of such resistance mechanisms are still lacking. ${ }^{6,13}$ Furthermore, old biofilms are highly resistant to antibiotics and antibacterial agents. ${ }^{11,14}$ It has previously been observed that tobramycin $(5 \mu \mathrm{g} / \mathrm{mL})$ kills $97 \%$ of the young (2 days) biofilms of Pseudomonas aeruginosa after 4 hours treatment. However, even a higher tobramycin concentration ( $50 \mu \mathrm{g} / \mathrm{mL})$ kills only $50 \%$ of the old ( 7 days) biofilms. ${ }^{15}$ Toté et $\mathrm{al}^{16}$ have found that different biocides reduce the number of viable $S$. aureus and $P$. aeruginosa cells in biofilms but the matrices of biofilms are not affected. Allan et al ${ }^{17}$ have shown that killing Escherichia coli cells with commercial disinfectants, in most cases, requires at least double the concentration of disinfectant when the cells were in biofilms compared with that needed for planktonic cells. Choi et al ${ }^{18}$ have reported a fourfold increase in the minimum bactericidal concentration (MBC) of silver nanoparticles (NPs) required for $E$. coli cells in biofilms compared with that needed for planktonic cells. Such tenacity of the formed biofilms is the leading cause to remove the infected orthopedic implants and to treat the infections before implanting new devices. ${ }^{19}$ Consequently, therapeutic modalities that could target the antibiotics, preventing the formation of biofilms, would be an effective way to control them. ${ }^{5}$

Generally speaking, silica $\left(\mathrm{SiO}_{2}\right)$-based formulations could be utilized for the targeted drug delivery and for squelching the intricate multidrug resistance. ${ }^{20,21}$ More specifically, $\mathrm{SiO}_{2}$ materials could be utilized as local antibiotic delivery systems in orthopedic implants targeting effective antibiotic concentrations in bone tissue and avoiding the drawbacks of systemic antibiotic administrations, like toxicity or limited tissue exposure. ${ }^{3}$ Aminoglycosides (i.e., gentamicin and kanamycin), glycopeptide antibiotics (i.e., vancomycin), and quinolones (i.e., ciprofloxacin) have broadly been utilized in orthopedic surgery, preventing or treating associated infections. ${ }^{1}$ There are a large number of published studies on loading antibiotics onto $\mathrm{SiO}_{2}$ materials for the prolonged localized drug delivery applications, as described for gentamicin ${ }^{22-27}$ and vancomycin. ${ }^{28,29}$ It has been demonstrated that kanamycin-resistant $E$. coli is susceptible to kanamycin-conjugated $\mathrm{SiO}_{2} \mathrm{NPs}$, though it is resistant to pristine kanamycin, because of the modified antibacterial mechanism of action of kanamycin conjugated to $\mathrm{SiO}_{2} \mathrm{NPs} .{ }^{30}$ However, none of those above studies has investigated the antibiofilm effects of antibiotic-loaded $\mathrm{SiO}_{2}$ NPs against $S$. aureus biofilms to ascertain their efficacy in orthopedic applications.

In our previous research, ${ }^{27}$ we have demonstrated better antibacterial effects of silica-gentamicin $\left(\mathrm{SiO}_{2}-\mathrm{G}\right)$ nanohybrids against Bacillus subtilis than Pseudomonas fluorescens or E. coli. However, further research is needed on bacterial strains most commonly involved in orthopedic applications, like $S$. aureus and their biofilms, to reveal the practical potential of the nanohybrids. Therefore, this study determines the antibacterial and antibiofilm effects of $\mathrm{SiO}_{2}-\mathrm{G}$ nanohybrids against MRSA and MRSA biofilms, respectively, for promising orthopedic applications. Bacterial motility constitutes a critical virulence factor in bacterial colonization by initiating the contact of bacterial cells with surfaces. ${ }^{8}$ A recent study ${ }^{31}$ has paid attention to the role of bacterial morphology in adhesion to immobilized liquid layers under dynamic conditions, advocating the more efficient adhesion of $E$. coli cells in comparison with that of $S$. aureus and $P$. aeruginosa, under dynamic conditions, to the flagella of E. coli. Furthermore, the most predominant clinical bacteria involved in orthopedic implant infections belong to the Staphylococcus genus followed by Enterobacteriaceae genus. Infections by Enterobacteriaceae are encountered with implants being surgically incised near to prenieums. ${ }^{32}$ The well-known genetics and the wealth of other knowledge collected on $E$. coli support its use as an exemplary model for studying the formation of biofilms. ${ }^{8}$ Therefore, the present study aims to enhance the understanding of the antibiofilm effects of the $\mathrm{SiO}_{2}-\mathrm{G}$ nanohybrids by also exploring such effects on $E$. coli biofilms.

Despite the importance of $\mathrm{SiO}_{2}-\mathrm{G}$ delivery systems, the safety and risks associated with their use have not been widely documented. Combining in vitro and in vivo toxicological data on nanomaterials, concerning their physicochemical properties, can help in predicting safety when designing nanomaterials. ${ }^{33}$ However, studies on the subject have been conflicting and mostly restricted to $\mathrm{SiO}_{2}$ NPs. Some studies have shown that $\mathrm{SiO}_{2}$ NPs decrease the viability of different cell lines such as that of human brain microvessel endothelial cells, ${ }^{34}$ human umbilical vein endothelial cells, ${ }^{35}$ and human lung epithelial BEAS-2B cells (only at $\geq 500 \mu \mathrm{g} / \mathrm{mL}$ of positively charged $\mathrm{SiO}_{2} \mathrm{NPs}$ with a diameter of $\left.\geq 100 \mathrm{~nm}\right) .{ }^{36}$ 
It has also been shown that $\mathrm{SiO}_{2}$ NPs significantly decrease the differentiation capacity of human mesenchymal stem cells. ${ }^{37}$ By contrast, a detailed examination of the toxicity of $\mathrm{SiO}_{2}$ NPs in 19 different cell lines has demonstrated minimal toxicity in all the cell lines tested. ${ }^{38} \mathrm{We}$ have recently defined the in vitro effects of $\mathrm{SiO}_{2}-\mathrm{G}$ nanohybrids $(719 \pm 128 \mathrm{~nm})$ on the osteogenesis of human osteoblast-like SaOS-2 cells, detecting a lower expression of the alkaline phosphatase but enhanced mineralization of the extracellular matrix at $250 \mu \mathrm{g} / \mathrm{mL} .{ }^{39}$ To better control the safety of such delivery systems, it is of paramount importance to couple the in vitro toxicological effects of these engineered nanomaterials with in vivo studies in more complex animal models. ${ }^{40}$ Zebrafish embryos are an outstanding animal model for screening chemical toxicity and nanotoxicity in vivo due to several advantages: 1) the genome similarity between zebrafish and humans makes the screening relevant to human health; 2) pores (diameter of $0.5-0.7 \mu \mathrm{m}$ ) in zebrafish chorions allow for the permeation of xenobiotics; 3 ) the transparency of embryos permits microscopic imaging; 4) the survival of embryos in the absence of functional cardiovascular system facilitates accurate cardiotoxicity studies. ${ }^{41}$ Another crucial aspect making zebrafish embryos an excellent animal model is that they have, similar to human embryos, protruded yolk sacs that supply proteins, lipids, and micronutrients, facilitating the growth of embryos. ${ }^{42}$ In the context of bone research, the key regulators of bone formation are also similar in zebrafish and mammals, providing a possibility to correlate the findings in zebrafish to mammalian bone metabolism. ${ }^{43-45}$ Taking advantage of their transparency, chondrocytes and osteoblasts can be conveniently monitored over time. ${ }^{43}$ Duan et $\mathrm{al}^{46}$ have demonstrated that $\mathrm{SiO}_{2}$ NPs (diameter of $62 \mathrm{~nm}$; 0.1 and $0.2 \mathrm{mg} / \mathrm{mL}$ ) significantly decrease the hatching rates and increase the mortalities of zebrafish embryos. These previous results, however, differ from those of Sharif et al, ${ }^{47}$ who did not detect toxic effects for the injected mesoporous $\mathrm{SiO}_{2} \mathrm{NPs}$ (diameter of $200 \mathrm{~nm} ; 10 \mathrm{mg} / \mathrm{mL}$ ) in zebrafish embryos, defining such $\mathrm{SiO}_{2}$ NPs as a suitable delivery system. Therefore, to clarify the nebulous and conflicting toxicity data of $\mathrm{SiO}_{2}$ NPs among in vitro and in vivo studies, we have also studied, in the present work, the in vivo toxic effects of $\mathrm{SiO}_{2}-\mathrm{G}$ nanohybrids in zebrafish embryos. To the best of our knowledge, this is the first study to explore the toxic effects of $\mathrm{SiO}_{2}-\mathrm{G}$ nanohybrids in this experimental model. Drawing upon the present two avenues of research on $\mathrm{SiO}_{2}-\mathrm{G}$ nanohybrids for safe orthopedic applications, the present study first attempts to demonstrate the antibacterial effects of $\mathrm{SiO}_{2}-\mathrm{G}$ nanohybrids against planktonic MRSA and their antibiofilm effects against
MRSA and E. coli biofilms and second, assesses their in vivo toxic effects in zebrafish embryos.

\section{Materials and methods Materials}

The gentamicin sulfate, tetraethyl orthosilicate ( $\geq 99.0 \%$ ), and ammonium hydroxide $(28 \%-30 \%)$ were obtained from Sigma-Aldrich Co. (St Louis, MO, USA). The MRSA strain (S. aureus subsp. aureus ATCC ${ }^{\circledR} 43300^{\text {TM}}$; KWIK-STIK ${ }^{\text {TM }}$ ) was purchased from Microbiologics ${ }^{\circledR}$ (St Cloud, MN, USA) and the E. coli strain (ATCC $11775^{\mathrm{TM}}$ ) was obtained from VTT Culture Collection. The Calgary biofilm device (CBD), commercially available as the MBEC TM (minimum biofilm eradication concentration) biofilm inoculator with a 96-well base and hydroxyapatite-coated pegs (19131) was purchased from Innovotech Inc. (Edmonton, AB, Canada).

\section{Synthesis of $\mathrm{SiO}_{2}-\mathrm{G}$ nanohybrids and pristine $\mathrm{SiO}_{2} \mathrm{NPs}$}

The $\mathrm{SiO}_{2}-\mathrm{G}$ nanohybrids were prepared according to the procedure used by Corrêa et al. ${ }^{48}$ Five hundred milligrams of gentamicin sulfate was dissolved in $10 \mathrm{~mL}$ of tetraethyl orthosilicate and $20 \mathrm{~mL}$ of ammonium hydroxide was then added to the solution, which was subjected to stirring for 20 minutes at ambient temperature until precipitation. Following precipitation, the material was dried overnight at ambient temperature and then ground. The pristine $\mathrm{SiO}_{2}$ NPs were prepared using the same procedure without adding gentamicin sulfate.

\section{Characterization of $\mathrm{SiO}_{2}-\mathrm{G}$ nanohybrids and pristine $\mathrm{SiO}_{2} \mathrm{NPs}$}

The prepared materials were then characterized by scanning electron microscope (SEM), zeta potential analyses, transmission electron microscope (TEM), and attenuated total reflectance-Fourier transform infrared (ATR-FTIR) spectroscopy. The SEM analyses were performed to analyze the surface morphology of the materials prepared, using Zeiss Sigma VP SEM with an acceleration voltage of $1.5 \mathrm{kV}$ and a secondary electron detector. Before SEM analyses, the samples were sputter coated with a platinum $(\mathrm{Pt})$ target for 1.5 minutes (yielding a Pt layer of $\sim 8.6 \mathrm{~nm}$ thickness), using an Emitech K100X sputter coater. The zeta potential of the materials suspended in deionized water was measured using the SZ-100 nanopartica Zetasizer (Horiba Scientific, Kyoto, Japan) in triplicate. The TEM studies were performed using a Hitachi TEM (H-7650B, Hitachi, Tokyo, Japan) and a JEOL TEM (JEM-2800, JEOL, Tokyo, Japan) microscopes with an acceleration voltage of $80 \mathrm{kV}$ and $200 \mathrm{kV}$, 
respectively. The size of the pristine $\mathrm{SiO}_{2} \mathrm{NPs}$ was analyzed on the obtained TEM images, whereas the size of the $\mathrm{SiO}_{2}-\mathrm{G}$ nanohybrids was analyzed on the obtained SEM and TEM images, trying to capture less aggregated particles. The size analysis was executed using Fiji ImageJ software. ATR-FTIR was recorded using a Nicolet 380 FT-IR (Thermo Electron Corporation, White Bear Lake, MN, USA) spectrometer, with a resolution of $2 \mathrm{~cm}^{-1}$ and a scan range of 4,000-500 $\mathrm{cm}^{-1}$. The spectra were the means of 64 scans.

\section{Antibacterial and antibiofilm tests}

The MRSA and E. coli strains were cultivated aerobically on Luria-Bertani agar overnight at $35^{\circ} \mathrm{C}$. The disinfection of the powder form $\mathrm{SiO}_{2}-\mathrm{G}$ nanohybrids and pristine gentamicin was conducted by UV irradiation (GS Gene Linker ${ }^{\circledR}$ UV Chamber, Bio-Rad Laboratories Inc., Hercules, CA, USA) for 90 seconds before the antibacterial and antibiofilm tests. Following disinfection, $\mathrm{SiO}_{2}-\mathrm{G}$ nanohybrids and gentamicin were suspended and dissolved in sterile deionized water ( $1 \mathrm{mg} / \mathrm{mL}$ ), respectively. The suspended $\mathrm{SiO}_{2}-\mathrm{G}$ nanohybrids were then sonicated for 30 minutes (VWR ${ }^{\circledR}$ Ultrasonic Bath, USC $200 \mathrm{~T}$, power $60 \mathrm{~W}$, ultrasonic frequency $45 \mathrm{kHz}$ ), obtaining homogeneous solutions, before the tests. The CBD was used to determine the susceptibilities of the biofilms to the materials tested. A universal neutralizer $(1.0 \mathrm{~g}$ L-histidine, $1.0 \mathrm{~g}$ L-cysteine, and $2.0 \mathrm{~g}$ reduced glutathione in $20 \mathrm{~mL}$ double distilled water) was prepared, sterilized using a $0.2 \mu \mathrm{m}$ cellulose acetate membranes, and stored at $-20^{\circ} \mathrm{C}$. Five milliliters of the prepared universal neutralizer was then added to $200 \mathrm{~mL}$ Mueller-Hinton broth (MHB) to be further added into the wells of the recovery plates used in the biofilm susceptibility tests.

\section{Agar diffusion assay}

The susceptibility tests were conducted on the planktonic MRSA cells following the guidelines described by the Clinical and Laboratory Standards Institute (CLSI).$^{49}$ Briefly, aliquots of $100 \mu \mathrm{L}$ of MRSA suspension $\left(\sim 1-2 \times 10^{8}\right.$ colonyforming units [CFUs]/mL) were spread on Mueller-Hinton agar plates. Aliquots of $50 \mu \mathrm{L}$ of $\mathrm{SiO}_{2}-\mathrm{G}$ nanohybrids $(1 \mathrm{mg} / \mathrm{mL})$ and pristine gentamicin $(1 \mathrm{mg} / \mathrm{mL}$ and $25 \mu \mathrm{g} / \mathrm{mL})$ were then dispensed into the $5 \mathrm{~mm}$-diameter wells of the plates. Following overnight incubation of the plates at $35^{\circ} \mathrm{C}$, the diameters of inhibition zones (IZs, mm) were measured. Three separate experiments were performed on different days. The results were interpreted following the tables of the CLSI document. ${ }^{50}$

\section{Minimum inhibitory concentration (MIC) and $\mathrm{MBC}$}

The MIC of the $\mathrm{SiO}_{2}-\mathrm{G}$ nanohybrids and pristine gentamicin against planktonic MRSA cells was determined using the broth microdilution method following the guidelines of the CLSI. ${ }^{51}$ Twofold serial dilutions (from $1 \mathrm{mg} / \mathrm{mL}$ to $1 \mu \mathrm{g} / \mathrm{mL}$ ) of the $\mathrm{SiO}_{2}-\mathrm{G}$ nanohybrids and pristine gentamicin were prepared in MHB in the wells of a microtiter plate. Within 15 minutes of the inoculum preparation (density adjusted to the same turbidity as McFarland standard 0.5), the inoculum was diluted and then inoculated into the wells (10 $\mu \mathrm{L}$ per well), achieving a final bacterial concentration of $5 \times 10^{5} \mathrm{CFU} / \mathrm{mL}$ and representing $10 \%$ of the volume per well. Uninoculated MHB was used as a negative control, and an MRSA suspension was used as a positive control for growth. The MICs were visually recorded after overnight incubation at $35^{\circ} \mathrm{C}$ in sealed plastic bags to avoid drying. To detect bacterial eradication by the materials tested, the $\mathrm{MBC}$ was detected following the guidelines of the CLSI, ${ }^{52}$ using the microdilution endpoints. Aliquots of $10 \mu \mathrm{L}$ of the wells showing the MICs (clear) were spot plated on MuellerHinton agar plates. The number of the cultured colonies was used to determine the bactericidal endpoints based on the final inoculum $\left(5 \times 10^{5} \mathrm{CFU} / \mathrm{mL}\right)$ and the rejection values of the tables of the CLSI. ${ }^{52}$ Two separate experiments were performed on different days.

\section{Biofilm susceptibilities using CBD}

Aliquots $(150 \mu \mathrm{L})$ of MRSA and E. coli dilutions (final bacterial concentrations of $\sim 10^{5}-10^{6} \mathrm{CFU} / \mathrm{mL}$ ) were added into the wells of the 96-well microtiter plates of the MBEC biofilm inoculator, excluding the sterility control wells (only MHB). The peg lids were then inserted into the plates, and the devices were incubated, under dynamic conditions, in a shaking incubator (110 rpm) for 24 hours at $35^{\circ} \mathrm{C}$. Specified pegs were removed from the lids, using sterilized pliers, and put into the wells of a 96-well microtiter plate containing MHB $(200 \mu \mathrm{L})$. The biofilms were detached by shaking for 30 minutes $(160 \mathrm{rpm})$. The biofilm viabilities were then detected by serially diluting and spot plating $(20 \mu \mathrm{L})$.

Another 96-well microtiter plate was used as the antibacterial challenge plate. The working solutions of the $\mathrm{SiO}_{2}-\mathrm{G}$ nanohybrids and pristine gentamicin were used as $1 \times, 2 \times$, and $4 \times$ of their MICs against planktonic cells of MRSA and E. coli. The concentrations of the $\mathrm{SiO}_{2}-\mathrm{G}$ nanohybrids tested were $500,1,000$, and $2,000 \mu \mathrm{g} / \mathrm{mL}$ and 250,500 , and $1,000 \mu \mathrm{g} / \mathrm{mL}$ against the biofilms of MRSA 
and $E$. coli, respectively. The concentrations of the pristine gentamicin tested were 125,250 , and $500 \mu \mathrm{g} / \mathrm{mL}$ and 7.8 , 15.6 , and $31.3 \mu \mathrm{g} / \mathrm{mL}$ against the biofilms of MRSA and $E$. coli, respectively. The contact time with the materials was set as 24 hours in a shaking incubator. A rinse plate was also prepared by adding $200 \mu \mathrm{L}$ of sterile saline $(0.9 \%)$ per well. The peg lids containing the biofilms were immersed in saline before and after the antibacterial challenge for 2 minutes, rinsing the dispersed cells from the biofilms.

After the challenge, the MBEC peg lid was transferred to the recovery plate containing $200 \mu \mathrm{L}$ of the universal neutralizer per well. The pegs were neutralized in the recovery plate for 30 minutes to equilibrate the antibacterial materials tested and the biofilms were detached by shaking (160 rpm) for 30 minutes. Aliquots of $20 \mu \mathrm{L}$ were serially diluted and spot plated to detect the viable counts per peg using Equation 1. Then, aliquots of $20 \mu \mathrm{L}$ of fresh MHB medium were added to the wells of the recovery plates, which were then sealed and incubated for another 24 hours at $35^{\circ} \mathrm{C}$ with shaking (110 rpm). The MBEC was visually detected after the incubation as the minimal concentration of the materials tested eradicating the MRSA biofilms. Two separate experiments were performed on different days. Each separate experiment was performed in triplicate.

$$
\log _{10}\left(\frac{\mathrm{CFU}}{\mathrm{Peg}}\right)=\log _{10}\left[\left(\frac{\mathrm{X}}{\mathrm{B}}\right)(\mathrm{D})+1\right]
$$

X, CFU counted on spot plate; B, volume plated; D, dilution factor.

SEM examination was also executed on the biofilms formed onto the CBD pegs following the standard protocol described by Harrison et $\mathrm{al}^{53}$ with modifications. Briefly, after the antibacterial challenge and rinsing, the desired pegs were broken from the lid by sterilized pliers. The broken pegs were rinsed for 15 minutes in $200 \mu \mathrm{L}$ sterile saline $(0.9 \%)$ in the wells of a 96-well microtiter plate, removing the dispersed planktonic cells from the pegs. The pegs were then placed in sterile Eppendorf Tubes $(2 \mathrm{~mL})$ and fixed by adding $300 \mu \mathrm{L}$ of $5 \%$ glutaraldehyde in $0.1 \mathrm{M}$ cacodylate buffer $(\mathrm{pH}$ 7.4) and kept at $4^{\circ} \mathrm{C}$ for 24 hours. After this fixation, the pegs were washed first with cacodylate buffer $(0.1 \mathrm{M}, 300 \mu \mathrm{L}, 15$ minutes $)$ and second with sterile distilled water $(300 \mu \mathrm{L}, 15$ minutes $)$. The pegs were postfixed with $1 \%$ cacodylate-buffered osmium tetroxide $(\mathrm{pH} 7.4)$ at room temperature for 1 hour. The pegs were then dehydrated using increased ethanol concentrations $(50 \%, 70 \%, 96 \%$, and $100 \%)$ and finally acetone (100\%), and critical point dried at 1,200 bar pressure at $40^{\circ} \mathrm{C}$ using liquid $\mathrm{CO}_{2}$. The samples were then mounted on aluminum stubs and sputter coated with a Pt target for 4 minutes (yielding a Pt layer of $\sim 22.8 \mathrm{~nm}$ thickness). All the samples were then analyzed using the Zeiss Sigma VP SEM with an acceleration voltage of $1.5 \mathrm{kV}$ and a secondary electron detector.

\section{Zebrafish strain and setup of exposure to $\mathrm{SiO}_{2}-\mathrm{G}$ nanohybrids}

The Tübingen strain of zebrafish (Danio rerio) was used in this study. The ethical approval was obtained from the Animal Care and Use Committee of Tsinghua University. The embryos were collected after natural spawning of adults maintained at the light:dark photoperiods of 14:10 hours and incubated in Holtfreter's medium at $28^{\circ} \mathrm{C} \pm 2^{\circ} \mathrm{C}$. The embryonic developmental stages were defined as previously reported by Kimmel et al. ${ }^{54}$ The collected embryos were placed in Petri dishes and examined by a stereomicroscope, removing dead embryos. The sterilization of the powder form $\mathrm{SiO}_{2}-\mathrm{G}$ nanohybrids was conducted by ${ }^{60} \mathrm{Co}$ irradiation at a dose of $10 \mathrm{kGy}$ before the in vivo experiments. At 4 hours post fertilization (hpf), the embryos were divided into three groups (30 embryos per group), and each group was placed into a separate well of a 6-well culture plate. The first group was exposed to pure Holtfreter's medium ( $3 \mathrm{~mL}$, with no test materials) and used as a negative control. The second and third groups were exposed to the $\mathrm{SiO}_{2}-\mathrm{G}$ nanohybrids in Holtfreter's medium at concentrations of 500 and $1,000 \mu \mathrm{g} / \mathrm{mL}$, respectively. The Holtfreter's medium (pure and containing the materials tested) was changed every 24 hours until the end of the experiment at 5 days post fertilization (dpf).

\section{Mortality, hatching, and cardiac rates}

Zebrafish embryos/larvae were evaluated for the toxic effects of the $\mathrm{SiO}_{2}-\mathrm{G}$ nanohybrids. The mortality rates were recorded every 24 hours, starting at $24 \mathrm{hpf}$, as the percentage of dead embryos/larvae of all embryos in the group. The hatching rates were recorded as the percentage of hatched embryos at $72 \mathrm{hpf}$ of all the living embryos in the group. The cardiac rates were detected by counting the beating of ventricles per minute under a stereomicroscope (Nikon SMZ 1500, Nikon Corporation, Tokyo, Japan) after being mounted in 3\% methylcellulose on the top of a depressed glass slide, starting at $72 \mathrm{hpf}$. Two separate experiments were performed on different days.

\section{Malformations of embryos/larvae}

The malformations of zebrafish embryos/larvae exposed to the $\mathrm{SiO}_{2}-\mathrm{G}$ nanohybrids were evaluated and counted every 
24 hours, starting at 24 hpf. The malformed embryos/larvae were mounted in 3\% methylcellulose on the top of a depressed glass slide, anesthetized by $0.1 \%$ tricaine, and captured using a stereomicroscope with Nikon Digital Sight camera (Ds-Ri1, Nikon Corporation). The phenotypic endpoints used to evaluate the malformations were pericardial sacs, yolk, body growth, spine, and tail. For estimating the severity of malformations and toxicity at exposure to the materials tested, the embryos/larvae were scored from 0 to 4 based on the conceptual scaling criteria proposed by Heiden et $\mathrm{al}^{55}$ with a slight modification. The scaling criteria were as follows: 0 , absence of malformations; 1 , single malformation; 2 , two malformations; 3, severe three or more malformations; and 4, lethality. The scoring spectrum $(1,2$, and 3 ; representing various degrees of malformations) values were determined at each time point and then accumulated, forging an average semiquantitative toxicity profile for each exposure group of the $\mathrm{SiO}_{2}-\mathrm{G}$ nanohybrids (see Supplementary materials). Score 0 represents the normally developed embryos/larvae, and score 4 represents the percentage of mortality. The percentage of malformed embryos/larvae was recorded every 24 hours of the living embryos in the group. An advantage of using the percentage of malformations is to identify the common malformations induced by $\mathrm{SiO}_{2}-\mathrm{G}$ nanohybrids in comparison with the control group. To achieve this, the percentage of malformation was also determined by dividing the number of embryos/larvae developed a specific type of malformation in the group by the total number of malformed embryos/larvae in all the groups. Two separate experiments were performed on different days.

\section{Statistical analysis}

The data obtained were analyzed using Student's $t$-tests (two-tailed, unequal variance) to determine the $P$-values using Microsoft Excel (Office Professional Plus 2016, Impressa Systems, Santa Rosa, CA, USA). The results were expressed as mean \pm standard deviation. Values of $P<0.05$ were considered statistically significant.

\section{Results and discussion}

\section{Characterization of $\mathrm{SiO}_{2}-\mathrm{G}$ nanohybrids and pristine $\mathrm{SiO}_{2} \mathrm{NPs}$}

The results obtained from the SEM analyses of the prepared pristine $\mathrm{SiO}_{2}$ NPs and $\mathrm{SiO}_{2}-\mathrm{G}$ nanohybrids are compared in Figure 1. The pristine $\mathrm{SiO}_{2}$ NPs (Figure 1A and C) demonstrate smooth spherical morphology that differs from the granular rough aggregated network of the $\mathrm{SiO}_{2}-\mathrm{G}$ nanohybrids (Figure 1B and D). This surface roughness of the $\mathrm{SiO}_{2}-\mathrm{G}$ nanohybrids validates the loading of gentamicin, providing means for the initial fast gentamicin release demonstrated in our previous study. ${ }^{27}$ It also matches with previous data that link the rough surfaces with the enhanced antibiotic release, ${ }^{56,57}$ especially at the initial stages of bone surgery to prevent osteomyelitis. ${ }^{58}$ The difference between the zeta potentials (surface charges) of the pristine $\mathrm{SiO}_{2}$ NPs and $\mathrm{SiO}_{2}-\mathrm{G}$ nanohybrids is highlighted in Figure 1E and was detected as $-61.6 \pm 0.9 \mathrm{mV}$ and $-9 \pm 1.5 \mathrm{mV}$, respectively. This decrease in the negative charge of the $\mathrm{SiO}_{2}-\mathrm{G}$ nanohybrids, compared with that of the pristine $\mathrm{SiO}_{2} \mathrm{NPs}$, is apparently attributed to the loaded gentamicin, suggesting an electrostatic interaction between the positively charged antibiotic and the negatively charged pristine $\mathrm{SiO}_{2} \mathrm{NPs}$. The present results are in accordance with those of Mebert et $\mathrm{al}^{59}$ who found that the most massive amount of positively charged gentamicin was incorporated into the most negatively charged $\mathrm{SiO}_{2}$ NPs by an adsorption process governed by electrostatic interactions.

The TEM images (Figure 2) envisage the remarkably different structures and mean diameters of the pristine $\mathrm{SiO}_{2}$ NPs and $\mathrm{SiO}_{2}-\mathrm{G}$ nanohybrids. It can be seen that the pristine $\mathrm{SiO}_{2}$ NPs (Figure 2A and $\mathrm{C}$ ) are somewhat monodisperse with a mean diameter (Figure 2E) of $293 \pm 21 \mathrm{~nm}$ and size distribution of 254-325 nm (Figure S1A). In contrast, the $\mathrm{SiO}_{2}-\mathrm{G}$ nanohybrids (Figure $2 \mathrm{~B}$ and $\mathrm{D}$ ) tend to unite and form aggregated networks with a striking increase in the mean diameter (Figure 2E) to $879 \pm 264 \mathrm{~nm}$ and a considerable variation in the size distribution of 453-1,248 nm (ㅍigure S1B). The decrease in the zeta potential after the gentamicin loading also contributes to the reduction in the repulsive forces of the nanohybrids, facilitating such network aggregation. This increase in size is consistent with our earlier observations, ${ }^{27,39}$ suggesting the loading of gentamicin onto the surface and in the $\mathrm{SiO}_{2}$ matrix. To some extent, this outcome supports that of Alvarez et $\mathrm{al}^{60}$ who detected an increase in the size of $\mathrm{SiO}_{2}$ from $441 \pm 5 \mathrm{~nm}$ to $511 \pm 38 \mathrm{~nm}$ after gentamicin loading with a slight decrease in the negative surface charge from $-47 \pm 5 \mathrm{mV}$ to $-43 \pm 7 \mathrm{mV}$, respectively. The observed correlation between the present dramatic increase in the size of the nanohybrids after gentamicin loading and the dramatic decrease in their negative charge might be explained in the following way: the more efficient decrease in the negative charge facilitates more efficient uniting of the nanohybrids and a more prominent increase in their size. Interestingly, additional thin layers are also observed on the surface of the $\mathrm{SiO}_{2}-\mathrm{G}$ nanohybrids (Figure 2D), representing the surfaceloaded gentamicin. This loaded gentamicin has also been 


\section{A}

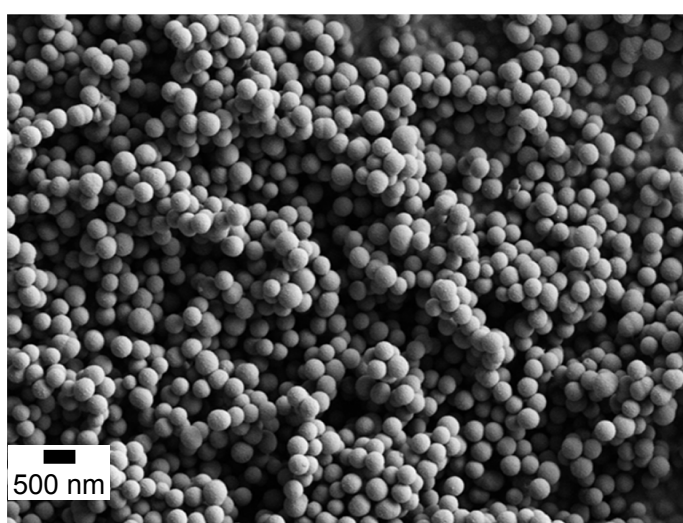

B

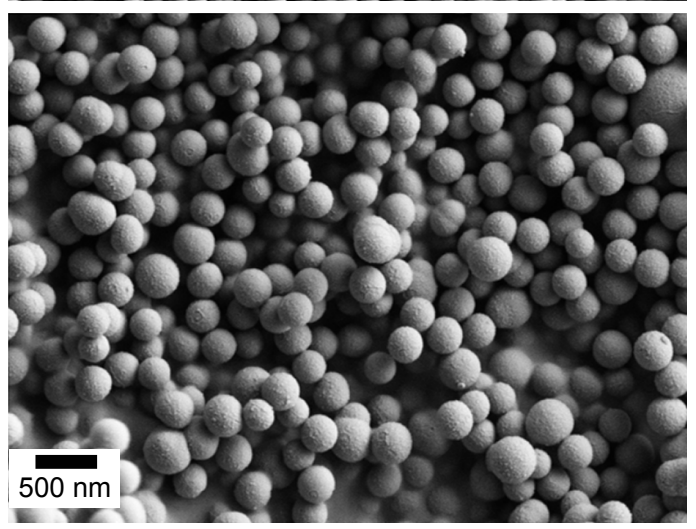

C

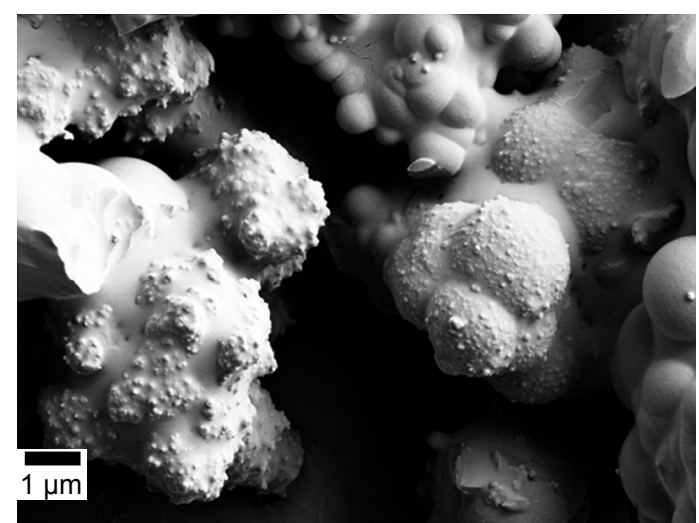

D

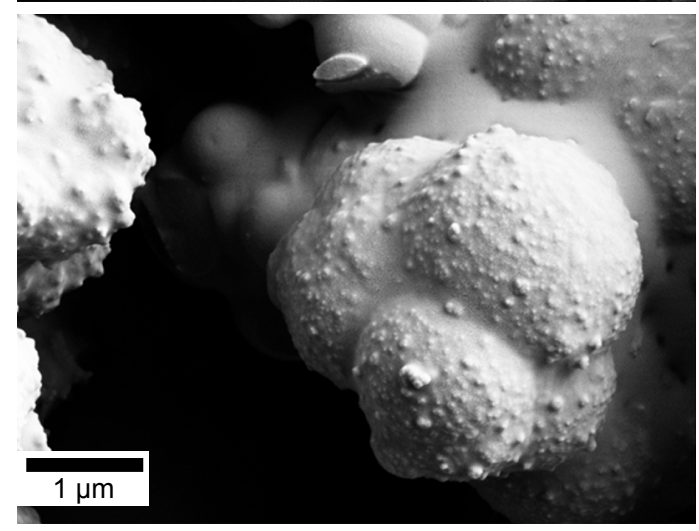

E

\section{Zeta potential (mV)}

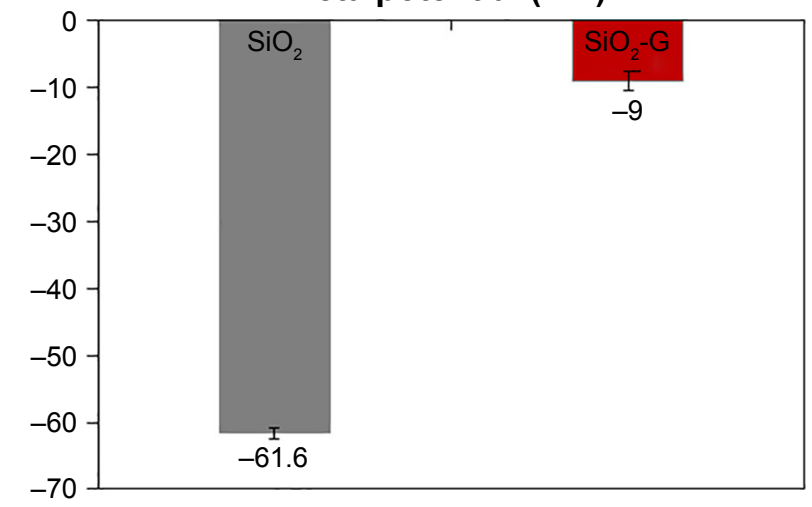

Figure I SEM images of the materials.

Notes: (A, C) Smooth spherical pristine $\mathrm{SiO}_{2} \mathrm{NPs}$ and (B, D) granular rough aggregated network of $\mathrm{SiO}_{2}-\mathrm{G}$ nanohybrids at the magnifications of I0,000 $\times($ A, B) and 20,000× (C, D). (E) The zeta potential of the pristine $\mathrm{SiO}_{2} \mathrm{NPs}_{\text {and }} \mathrm{SiO}_{2}-\mathrm{G}$ nanohybrids in deionized water. The error bars represent the standard errors of the means. Abbreviations: SEM, scanning electron microscope; $\mathrm{SiO}_{2} \mathrm{NPs}$, silica nanoparticles; $\mathrm{SiO}_{2}-\mathrm{G}$, silica-gentamicin.

reported by the appearance of the bands of gentamicin (see Supplementary materials) in the ATR-FTIR spectrum of the nanohybrids (Figure S2).

\section{Antibacterial effects of $\mathrm{SiO}_{2}-\mathrm{G}$ nanohybrids against planktonic MRSA cells}

To compare the antibacterial effects of the $\mathrm{SiO}_{2}-\mathrm{G}$ nanohybrids and pristine gentamicin, IZs were first measured in agar diffusion assays after 24 hours. It is somewhat surprising that no IZ was observed by pristine gentamicin $(25 \mu \mathrm{g} / \mathrm{mL})$. On the contrary, the $\mathrm{SiO}_{2}-\mathrm{G}$ nanohybrids $(1 \mathrm{mg} / \mathrm{mL})$, releasing the same concentration of gentamicin $(25.05 \mu \mathrm{g} / \mathrm{mL})$ after 24 hours as determined in our previous study, ${ }^{27}$ elicited IZs of $10.7 \pm 0.6 \mathrm{~mm}$ (Figure $3 \mathrm{~A}$ and $\mathrm{B}$ ). To find a reasonable inhibitory concentration of the $\mathrm{SiO}_{2}-\mathrm{G}$ nanohybrids against MRSA, the MIC and MBC were second identified against planktonic MRSA cells. According to the data in Figures 3C and $\underline{\mathrm{S}} 3$, the MICs and MBCs were 500 and $125 \mu \mathrm{g} / \mathrm{mL}$ for the $\mathrm{SiO}_{2}-\mathrm{G}$ nanohybrids and pristine gentamicin, respectively. 


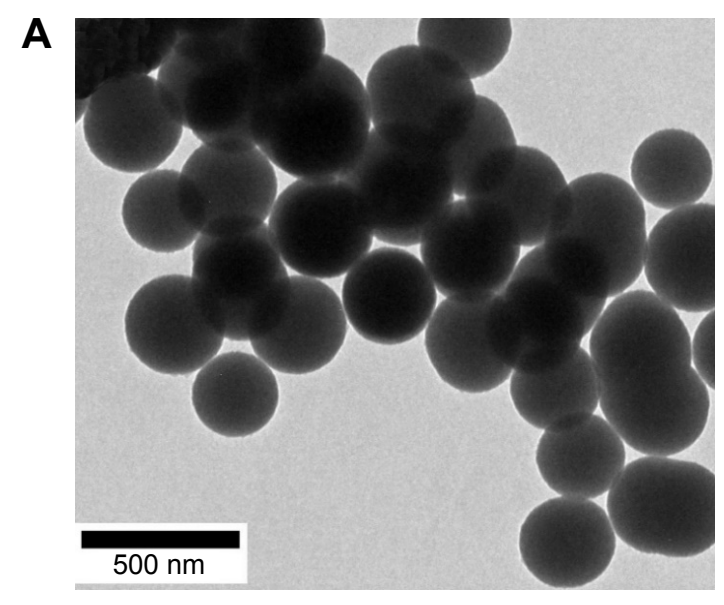

C

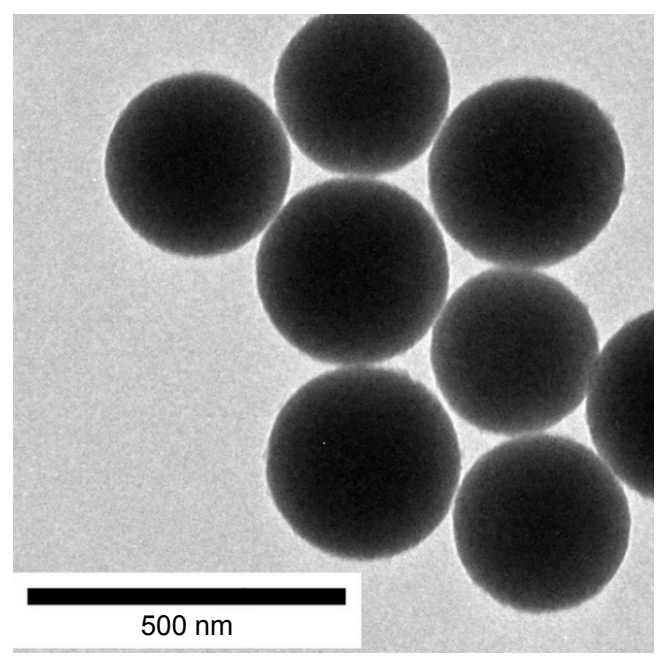

B

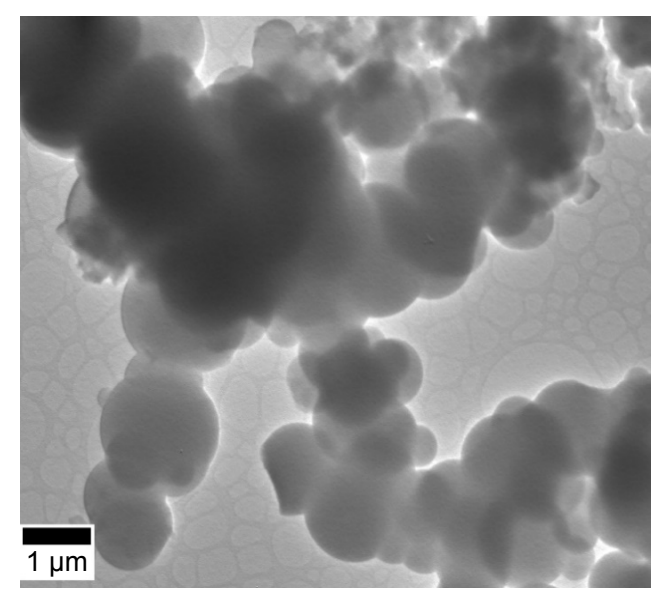

D

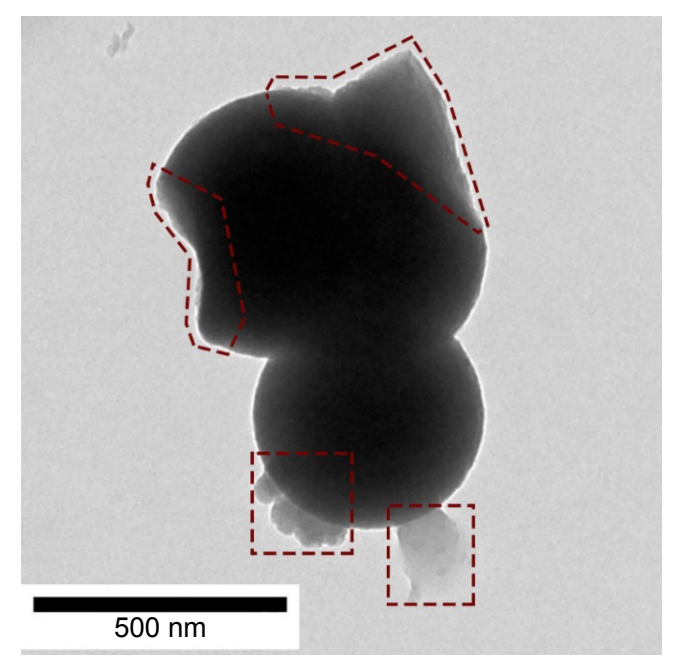

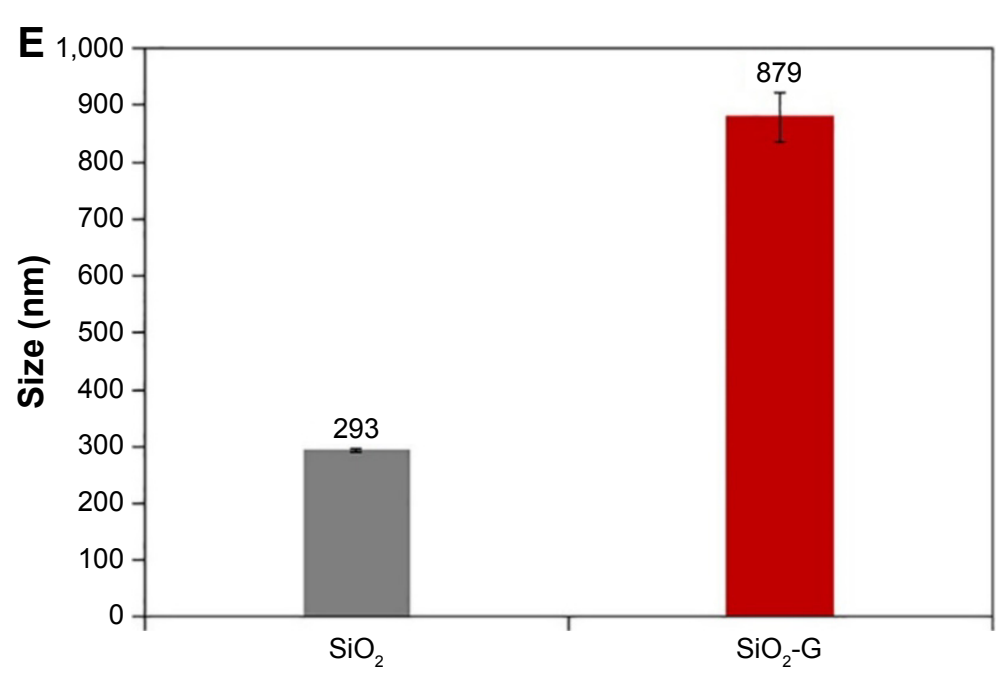

Figure 2 TEM images of the materials.

Notes: (A, C) Pristine $\mathrm{SiO}_{2} \mathrm{NPs}$ and (B, D) $\mathrm{SiO}_{2}-\mathrm{G}$ nanohybrids. The surface-loaded gentamicin is marked red with dashed shapes in panel D. Magnifications of $8,000 \times$ (A), $60,000 \times(\mathbf{B})$, and 10,000× (C, D). (E) The size of the pristine $\mathrm{SiO}_{2}$ and $\mathrm{SiO}_{2}-\mathrm{G}$ nanohybrids analyzed on the obtained TEM, and SEM and TEM images, respectively. The error bars represent the standard errors of the means.

Abbreviations: $\mathrm{SEM}$, scanning electron microscope; $\mathrm{SiO}_{2} \mathrm{NPs}$, silica nanoparticles; $\mathrm{SiO}_{2}$-G, silica-gentamicin; TEM, transmission electron microscope.

However, the $\mathrm{SiO}_{2}-\mathrm{G}$ nanohybrids release only $\sim 12.5 \mu \mathrm{g}$ gentamicin/mL at their $\mathrm{MIC},{ }^{27}$ indicating that the $\mathrm{SiO}_{2}-\mathrm{G}$ nanohybrids are aptly more effective than pristine gentamicin (MIC, $125 \mu \mathrm{g} / \mathrm{mL}$ ) to inhibit the tenacious MRSA cells.
The most explicit finding to emerge from the present tests is that the $\mathrm{SiO}_{2}-\mathrm{G}$ nanohybrids can overcome the resistance of MRSA against pristine gentamicin, by even releasing less gentamicin. The present results support a previous study, 

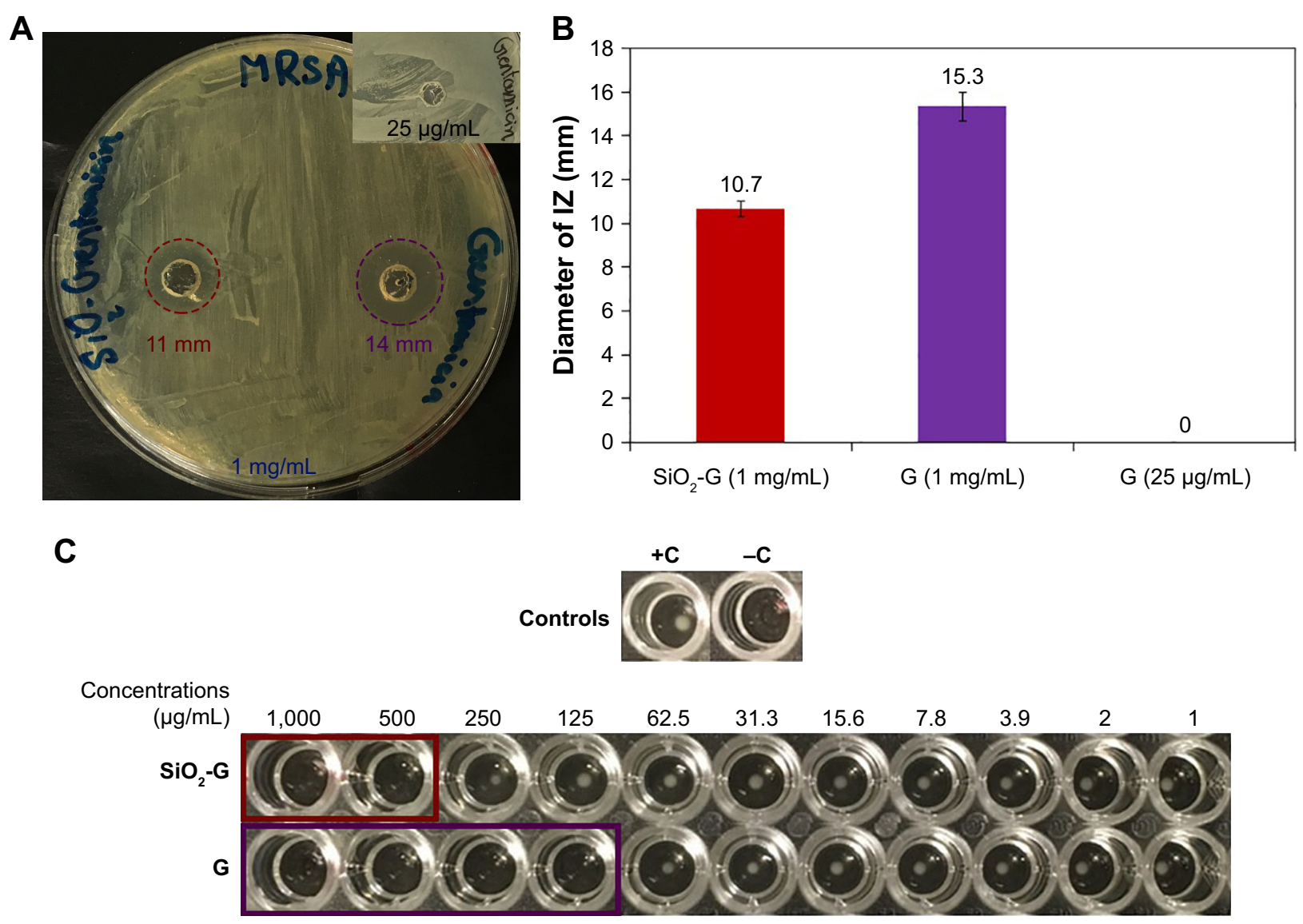

Figure 3 Antibacterial effects of the materials tested.

Notes: (A) Agar diffusion assay of the $\mathrm{SiO}_{2}-\mathrm{G}$ nanohybrids $(\mathrm{I} \mathrm{mg} / \mathrm{mL})$ and pristine gentamicin $(\mathrm{I} \mathrm{mg} / \mathrm{mL})$ against planktonic MRSA cells, highlighting the $\mathrm{IZs}$ with dashed red and violet circles, respectively. The inset shows the lack of IZ by pristine gentamicin $(25 \mu \mathrm{g} / \mathrm{mL})$. (B) The diameters of IZs. The error bars represent the standard errors of the means. (C) $M I C s$ of the $\mathrm{SiO}_{2}-\mathrm{G}$ nanohybrids $(500 \mu \mathrm{g} / \mathrm{mL})$ and pristine gentamicin $(\mathrm{G}, 125 \mu \mathrm{g} / \mathrm{mL})$ against planktonic $M R S A$ cells, highlighting the clear wells in SiO ${ }_{2}-\mathrm{G}$ nanohybrids and gentamicin assays with red and violet rectangles, respectively. $+\mathrm{C}$, positive control, an MRSA suspension showing a button of bacterial growth. $-\mathrm{C}$, negative control, uninoculated MHB.

Abbreviations: G, gentamicin; IZs, inhibition zones; MHB, Mueller-Hinton broth; MICs, minimum inhibitory concentrations; MRSA, methicillin-resistant Staphylococcus aureus; $\mathrm{SiO}_{2}-\mathrm{G}$, silica-gentamicin.

performed with biofilms, ${ }^{57}$ which showed that the reduction of $S$. aureus biofilm growth did not necessarily correlate with the amount of gentamicin released from different bone cement. Some bone cement showed a more significant reduction of $S$. aureus biofilms, by even releasing less gentamicin compared with other bone cement in the same study.

\section{Antibiofilm effects of $\mathrm{SiO}_{2}-\mathrm{G}$ nanohybrids and pristine gentamicin}

To determine the susceptibilities of the preformed MRSA and E. coli biofilms, under dynamic conditions, on the pegs of the $\mathrm{CBD}$ to the $\mathrm{SiO}_{2}-\mathrm{G}$ nanohybrids and pristine gentamicin tested, the viable counts of bacterial cells in biofilms were first compared after neutralization and plating as shown in Figure 4 and Table $S 1 . \log _{10}$ numbers of the viable counts of MRSA cells in the positive control biofilms are presented in Figure 4A. The viable counts of MRSA cells in the biofilms were not reduced after treatment with the different concentrations $(1 \times, 2 \times$, and $4 \times$ of the MICs recorded for the planktonic MRSA cells) of $\mathrm{SiO}_{2}$ - $\mathrm{G}$ nanohybrids and pristine gentamicin (Figure 4A). These nonreduced viable counts highlight the problem of the stubborn resistance of MRSA cells in biofilms. Interestingly, as shown in Figure 4B, there were significant differences between $\log _{10}$ numbers of the viable counts of $E$. coli cells in the positive control biofilms and the biofilms treated with the $\mathrm{SiO}_{2}-\mathrm{G}$ nanohybrids ( $P=0.002$ for the three concentrations tested) and pristine gentamicin ( $P=0.002$ for the highest concentration tested). $\mathrm{SiO}_{2}-\mathrm{G}$ nanohybrids had entirely eradicated the $E$. coli biofilms with an MBEC recorded as $250 \mu \mathrm{g} / \mathrm{mL}$. The correlation between the presently recorded $\mathrm{MBEC}$ of the $\mathrm{SiO}_{2}-\mathrm{G}$ nanohybrids against $E$. coli cells in biofilms and the same previously recorded MIC $(250 \mu \mathrm{g} / \mathrm{mL})$ against planktonic E. coli cells $^{27}$ is of interest. Counting CFUs in the biofilms is one of the principal ways to delineate the efficient diffusion of antibiotics through the biofilms, and an excellent antibiotic 

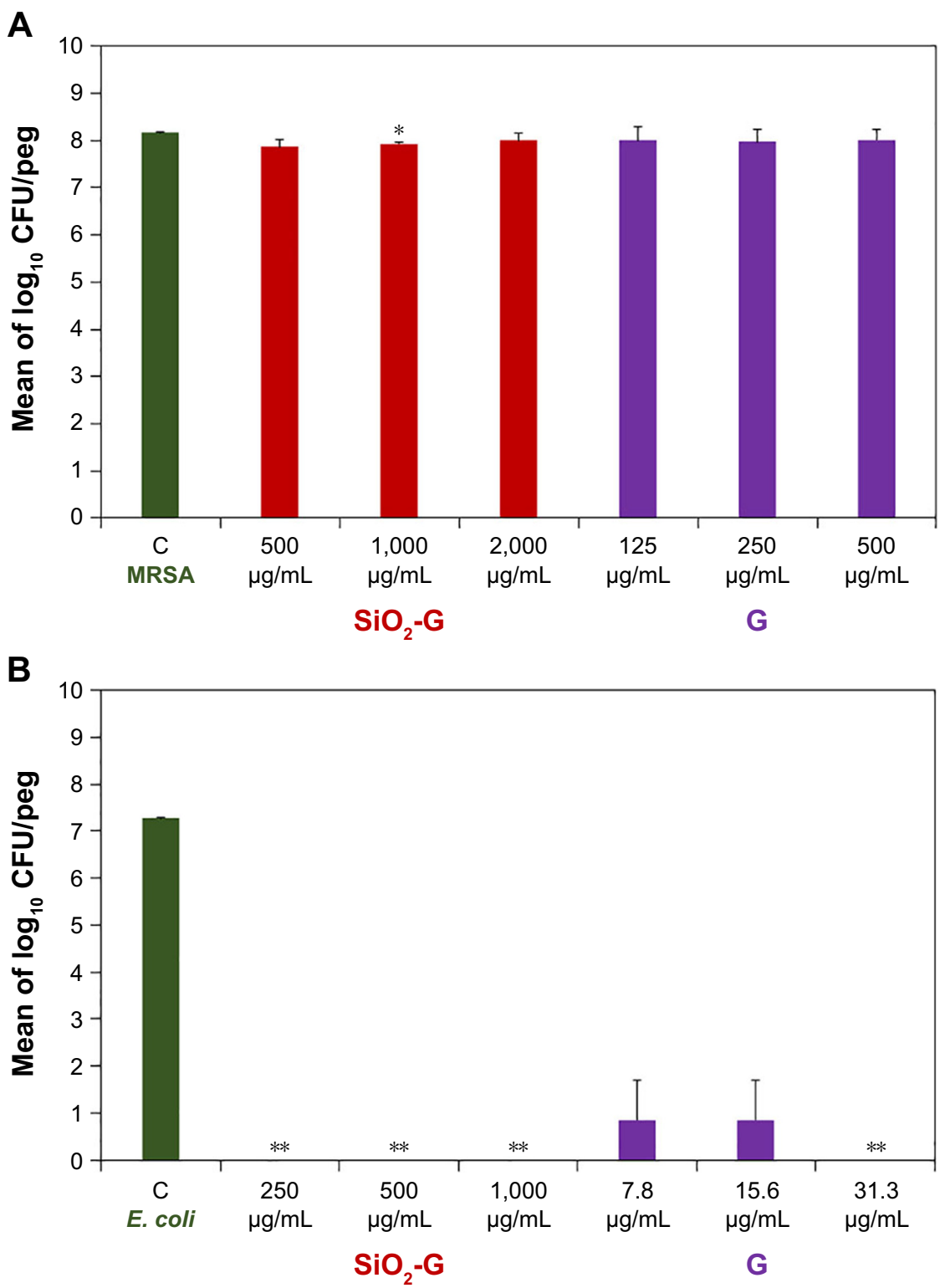

Figure 4 Antibiofilm effects of the materials tested.

Notes: Mean of $\log _{10}$ numbers of the viable cells (CFU/peg) in MRSA (A) and E. coli (B) biofilms counted by spot plating of the dispersed cells from the pegs after neutralization. The error bars represent the standard errors of the means. The data shown are representative of two separate experiments. $* P<0.05$ and $* * P<0.01$ indicate significant differences compared with the control using Student's t-test (two-tailed, unequal variance).

Abbreviations: $\mathrm{C}$, control; $\mathrm{CFU}$, colony-forming units; E. coli, Escherichia coli; G, gentamicin; MRSA, methicillin-resistant Staphylococcus aureus; SiO ${ }_{2}$-G, Silica-gentamicin.

diffusion is demonstrated by recording similar MICs for the cells in the biofilms and the planktonic form. ${ }^{9}$ This similar MBEC and $\mathrm{MIC}$ underpin the $\mathrm{SiO}_{2}-\mathrm{G}$ nanohybrids as a promising delivery system releasing effective gentamicin concentrations that diffuse through and entirely eradicate the E. coli biofilms. Pristine gentamicin also eradicated E. coli biofilms with an MBEC recorded as $7.8 \mu \mathrm{g} / \mathrm{mL}$ (Figure 4B), which places $E$. coli cells in biofilms within the intermediate range of susceptibility according to the MIC standards of the CLSI for planktonic cells. ${ }^{50}$
To further investigate the susceptibility of the preformed biofilms to the materials tested, the pegs of the CBD were visualized by SEM (Figures 5, S4 and $\underline{\mathrm{S} 5}$ ). The architecture of the MRSA biofilms (Figure 5A and B) appeared to be unaffected by the treatment with the $\mathrm{SiO}_{2}-\mathrm{G}$ nanohybrids and pristine gentamicin. In contrast, there were interesting differences between the architecture of the untreated $E$. coli biofilms and the biofilms treated with the $\mathrm{SiO}_{2}-\mathrm{G}$ nanohybrids and pristine gentamicin (Figure $5 \mathrm{C}$ and $\mathrm{D}$ ). $\mathrm{SiO}_{2}-\mathrm{G}$ nanohybrids seemed to orchestrate a holistic ultrastructural 

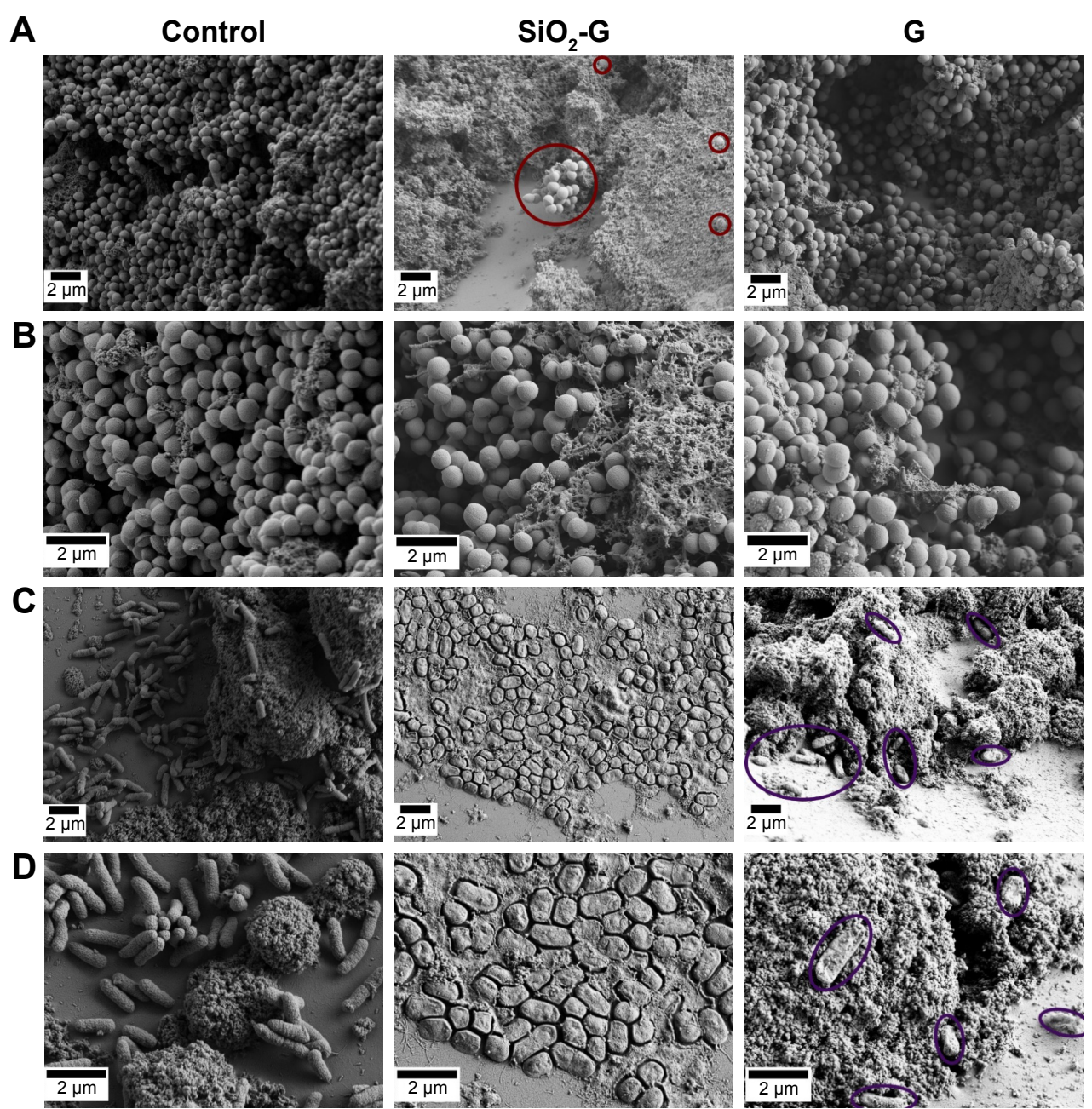

Figure 5 SEM images of the susceptibility of preformed biofilms to the materials tested.

Notes: (A, B) MRSA and (C, D) E. coli biofilms formed on the pegs of the CBD in the absence (control) or presence of the SiO $-\mathrm{G}_{2}$ nanohybrids or G, respectively, taken at the magnifications of $5,000 \times(\mathbf{A}, \mathbf{C})$ and $10,000 \times(\mathbf{B}, \mathbf{D})$. Red circles demonstrate the intact ultrastructure of the MRSA biofilms treated with the SiO ${ }_{2}-\mathrm{G}$ nanohybrids. Violet ellipses demonstrate scattered $E$. coli cells with a slightly deformed ultrastructure in biofilms treated with $G$.

Abbreviations: CBD, Calgary biofilm device; E. coli, Escherichia coli; G, pristine gentamicin; MRSA, methicillin-resistant Staphylococcus aureus; SEM, scanning electron microscope; $\mathrm{SiO}_{2}-\mathrm{G}$, silica-gentamicin.

deformation of the E. coli biofilms in the form of an utter deterioration of cell shapes and apt damage and wrinkling of their cell walls. E. coli biofilms treated with pristine gentamicin demonstrated a scattered distribution of few cells with a slightly deformed ultrastructure.

Due to the tedious techniques needed for cultivating and quantifying biofilm growth and subsequently adopting antimicrobial screening programs, it is of paramount importance to develop rapid screening methods for evaluating the antimicrobial susceptibilities of bacteria following biofilm formation. ${ }^{14}$ Consequently, we have utilized the CBD as a reliable and rapid method to detect the biofilm susceptibilities to the $\mathrm{SiO}_{2}-\mathrm{G}$ nanohybrids. The $\mathrm{CBD}$ can aptly reproduce biofilm formation and mimic in vivo biofilms, and it facilitates the characterization of the formed biofilms by microscopic techniques. ${ }^{9}$ A robust relationship between ultrasound waves and the destroyed ultrastructure of biofilms, increasing the bactericidal effect of antibiotics, has been reported in the literature. ${ }^{61}$ This relationship was exemplified in the work of Rediske et al, ${ }^{62}$ which illustrated that high-intensity ultrasonic pulses eradicate $E$. coli biofilms on subcutaneously implanted disks in rabbits receiving systemic gentamicin treatment with no adverse effects on the skin integrity. Furthermore, there is little agreement on the sonication time required to detach the biofilms, ranging from as short as 60 seconds in the modified Robbins device ${ }^{57,63}$ to 5 minutes in both 96-well polystyrene microtiter plates ${ }^{64}$ and the $\mathrm{CBD},{ }^{65}$ or also increasing in the CBD to 10 minutes ${ }^{66}$ and 30 minutes. ${ }^{17}$ van de Belt et al ${ }^{63}$ have 
also found that the continuous flow of medium in the modified Robbins device facilitates the detachment of fragments of the formed biofilms (24 hours) on the gentamicin-loaded bone cement. Consequently, high rates of shaking (160 rpm) for a long time (30 minutes), instead of sonication, were adopted in the present study to detach the biofilms. This shaking played a crucial role in excluding errors originating from the damage of bacterial cells in biofilms after ultrasonication, thus facilitating a more accurate quantification of viable cells in the biofilms. It also offered a way to exclude the inconsistency reported in the literature for the sonication time required to detach the biofilms.

The combination of the present findings suggests the following: first, the $\mathrm{SiO}_{2}-\mathrm{G}$ nanohybrids can combat the resistance of planktonic MRSA cells against pristine gentamicin. This combating of resistance facilitates the use of such delivery systems to prevent the formation of biofilms composed of stubborn MRSA strains. Second, $\mathrm{SiO}_{2}-\mathrm{G}$ nanohybrids can entirely eradicate the preformed $E$. coli biofilms but not MRSA biofilms. The deterioration of the shape and the reduction of the size of $E$. coli cells in biofilms treated with the $\mathrm{SiO}_{2}-\mathrm{G}$ nanohybrids are more pronounced and complete, as observed by SEM than seen with pristine gentamicin. Therefore, the $\mathrm{SiO}_{2}-\mathrm{G}$ nanohybrids can combat the virulence of $E$. coli cells in biofilms, which is mainly attributed to their flagella, allowing for surface colonization. ${ }^{8}$ The $\mathrm{SiO}_{2}-\mathrm{G}$ nanohybrids thus possess superior antibiofilm effects compared with pristine gentamicin. A recent $\operatorname{study}^{67}$ has reported a change in the surface charge of liposomal gentamicin from -54.5 to $17.5 \mathrm{mV}$ after association with lysozyme and speculated the role of this surface charge in the antibiofilm effects of the lysozyme-associated liposomal gentamicin. The change in surface charge might facilitate an electrostatic attraction of the positively charged lysozyme-associated liposomal gentamicin to the negative charge of alginate in the biofilm matrix. This change in the surface charge resembles, to some extent, our results showing the decrease of the negative charge from $-61.6 \pm 0.9 \mathrm{mV}$ to $-9 \pm 1.5 \mathrm{mV}$ for the pristine $\mathrm{SiO}_{2} \mathrm{NPs}_{\mathrm{s}}$ and $\mathrm{SiO}_{2}-\mathrm{G}$ nanohybrids, respectively. In contrast, prior studies ${ }^{68,69}$ have noted an intense inhibition of diffusion of the positively charged pristine gentamicin (aminoglycoside) through biofilm layers after binding to the negatively charged alginate in the biofilm matrix. Consequently, one of the remarkable findings to emerge from the present study is that $\mathrm{SiO}_{2}-\mathrm{G}$ delivery systems preserve the full utilization of the gentamicin released to combat preformed $E$. coli cells in biofilms, instead of being entirely sequestered by the negative charge of the biofilm matrix. While seeking a reasonable explanation for the absence of antibiofilm effects of the nanohybrids against MRSA cells in biofilms, it is noteworthy that another study ${ }^{70}$ has shown enhanced antibiofilm effects of an NP-stabilized capsule with a core of cinnamaldehyde dissolved in peppermint oil. In that study, the enhanced effects against MRSA biofilms were attributed to the cationic nature of the capsule enabling more interactions with the biofilms and the acidic nature of the biofilms breaking the capsule and releasing more cinnamaldehyde. Consequently, the surface charge of the present $\mathrm{SiO}_{2}-\mathrm{G}$ delivery systems enabled the full utilization of gentamicin against $E$. coli cells in biofilms but was not cationic enough to allow the interaction of the nanohybrids with MRSA biofilms.

\section{In vivo toxic effects of $\mathrm{SiO}_{2}-\mathrm{G}$ nanohybrids in zebrafish embryos/larvae}

To enable the use of $\mathrm{SiO}_{2}-\mathrm{G}$ nanohybrids as delivery systems in orthopedic applications, the possible toxicity of $\mathrm{SiO}_{2}-\mathrm{G}$ nanohybrids was assessed in vivo in the second avenue of the present research through evaluating a series of endpoints in zebrafish embryos/larvae. The exposure concentrations (500 and 1,000 $\mu \mathrm{g} / \mathrm{mL}$ ) represented multiples of the MIC of the planktonic MRSA cells $(1 \times$ and $2 \times)$ and MBEC of $E$. coli biofilms $(2 \times$ and $4 \times)$, respectively. The results obtained from the continuous monitoring of the mortality rates are presented in Figure 6A. The embryos exposed to the $\mathrm{SiO}_{2}-\mathrm{G}$ nanohybrids demonstrated higher mortality rates than the control group. However, this increase in the mortality rates was not significant $(P>0.05)$ and was mainly detected at the embryonic developmental stage of $24 \mathrm{hpf}$, as $13.4 \% \pm 9.4 \%$ and $15 \% \pm 7.1 \%$ at the exposure to 500 and $1,000 \mu \mathrm{g} / \mathrm{mL}$ of $\mathrm{SiO}_{2}-\mathrm{G}$ nanohybrids, respectively, in comparison with the $3.3 \%$ mortality in the control group. The mortality rate slightly increased over time (120 hpf) at the exposure to $500 \mu \mathrm{g} / \mathrm{mL}$ of the nanohybrids, reaching $16.7 \% \pm 9.4 \%$. Despite this, the mortality rates recorded at the exposure to $1,000 \mu \mathrm{g} / \mathrm{mL}$ of the nanohybrids and the control group remained consistent $24 \mathrm{hpf}$ and over the time (120 hpf), underpinning the absence of a time-dependent increase in the mortality rates. Concerning the hatching rates, all the embryos exposed to the $\mathrm{SiO}_{2}-\mathrm{G}$ nanohybrids (500 and 1,000 $\mu \mathrm{g} / \mathrm{mL}$ ) demonstrated normal $100 \%$ hatching rates after 72 hours, in the same way as the control group. A comparison of the continuous monitoring of the cardiac rates of the embryos/larvae exposed to the $\mathrm{SiO}_{2}-\mathrm{G}$ nanohybrids (500 and $1,000 \mu \mathrm{g} / \mathrm{mL}$ ) and the control group are presented in Figure 6B and Table S2. The embryos/larvae revealed a slight nonsignificant increase 

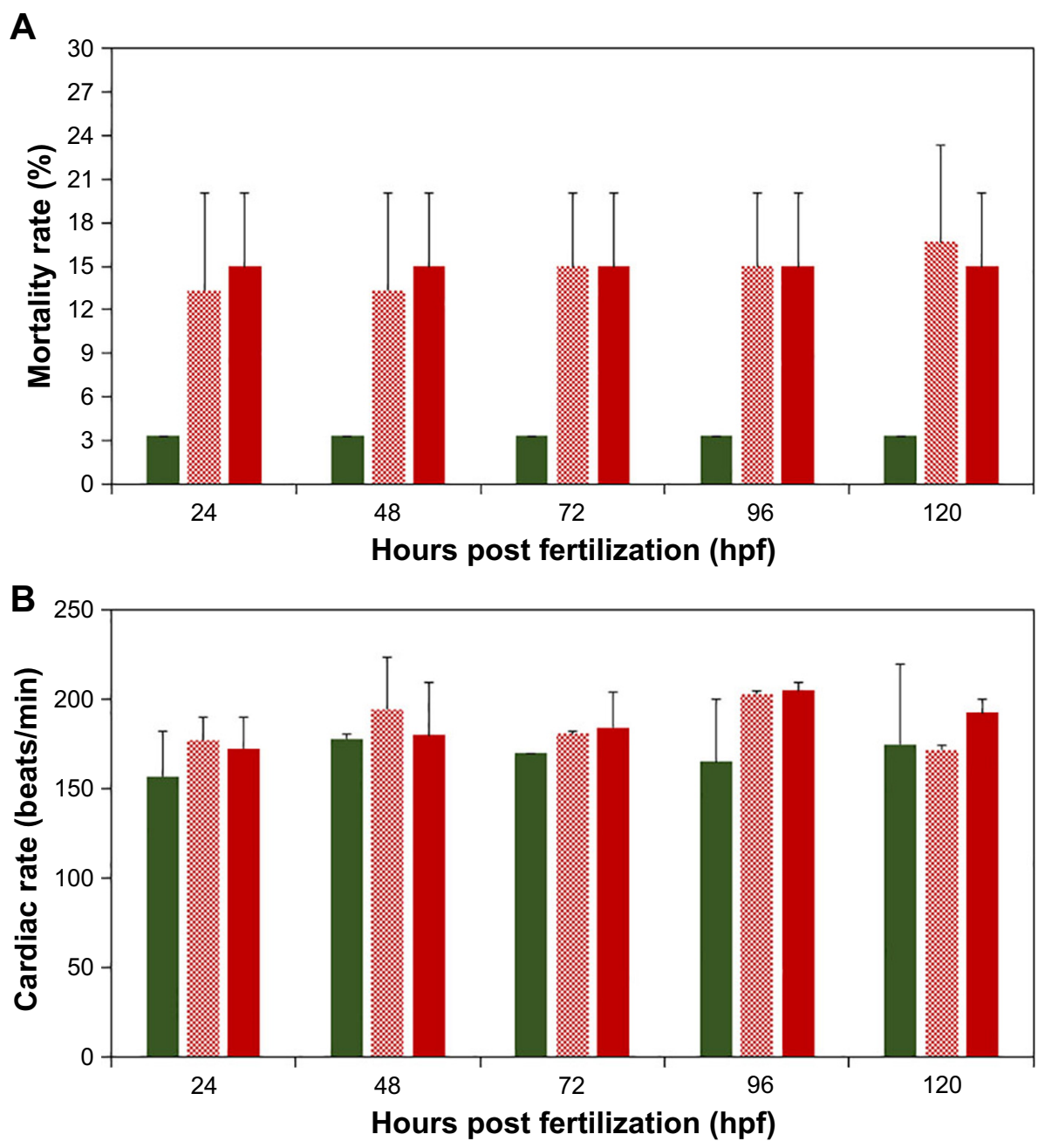

口C $\otimes \mathrm{SiO}_{2}-\mathrm{G}(500 \mu \mathrm{g} / \mathrm{mL}) \quad \square \mathrm{SiO}_{2}-\mathrm{G}(1,000 \mu \mathrm{g} / \mathrm{mL})$

Figure 6 In vivo toxic effects of the materials tested.

Notes: (A) Mortality and (B) cardiac rates of zebrafish embryos/larvae exposed to the $\mathrm{SiO}_{2}-\mathrm{G}$ nanohybrids $(500$ and I,000 $\mu \mathrm{g} / \mathrm{mL})$. The mortality rates demonstrated a nonsignificant increase mainly $24 \mathrm{hpf}$, after exposure to the nanohybrids at the concentrations of 500 and I,000 $\mu \mathrm{g} / \mathrm{mL}$. Embryos/larvae exposed to the nanohybrids demonstrated a slight tachycardia at the concentrations of 500 and I,000 $\mu \mathrm{g} / \mathrm{mL}$. The error bars represent the standard errors of the means of two separate experiments, 30 embryos in each group. All the $P$-values are $>0.05$ compared with the control group using Student's $t$-tests (two-tailed, unequal variance).

Abbreviations: $\mathrm{C}$, control group; $\mathrm{SiO}_{2}-\mathrm{G}$, silica-gentamicin.

$(P>0.05)$ in the cardiac rates (tachycardia) at the exposure to the $\mathrm{SiO}_{2}-\mathrm{G}$ nanohybrids at the two concentrations tested. This tachycardia indicates that the $\mathrm{SiO}_{2}-\mathrm{G}$ nanohybrids may lead to slight cardiac arrhythmias.

In Figure 7, images of the control group provide an overview of the normal developmental stages of zebrafish embryos/larvae. The exposure of embryos/larvae to the $\mathrm{SiO}_{2}-\mathrm{G}$ nanohybrids ( 500 and $1,000 \mu \mathrm{g} / \mathrm{mL}$ ) ignites the scenery with a throng of sublethal malformations (Figure 7 and Figure S6), including pericardial edema; yolk sac edema (YSE) or yolk not depleted (YND); stunted growth (SG); spinal deformity (SD); and tail malformation (TM) or broken tail (BT).
To address a semiquantitative toxicity profile for each exposure group of the $\mathrm{SiO}_{2}-\mathrm{G}$ nanohybrids (500 and 1,000 $\mu \mathrm{g} / \mathrm{mL}$ ), the scoring spectrum $(1,2$, and 3; defining various degrees of malformations) values were determined at each time point and then accumulated. The normally developed embryos/ larvae represent score 0 . The dead embryos/larvae represent score 4 and were recognized in the mortality recordings. The scoring spectra and cumulative values are shown in Table S3 and Figure S7. A closer inspection of the average cumulative scores and the exposure concentrations demonstrate that the lower exposure concentration $(500 \mu \mathrm{g} / \mathrm{mL})$ showed average cumulative scores of $25,25.9 \pm 14.6$, and $30.9 \pm 18.1$ for scores 

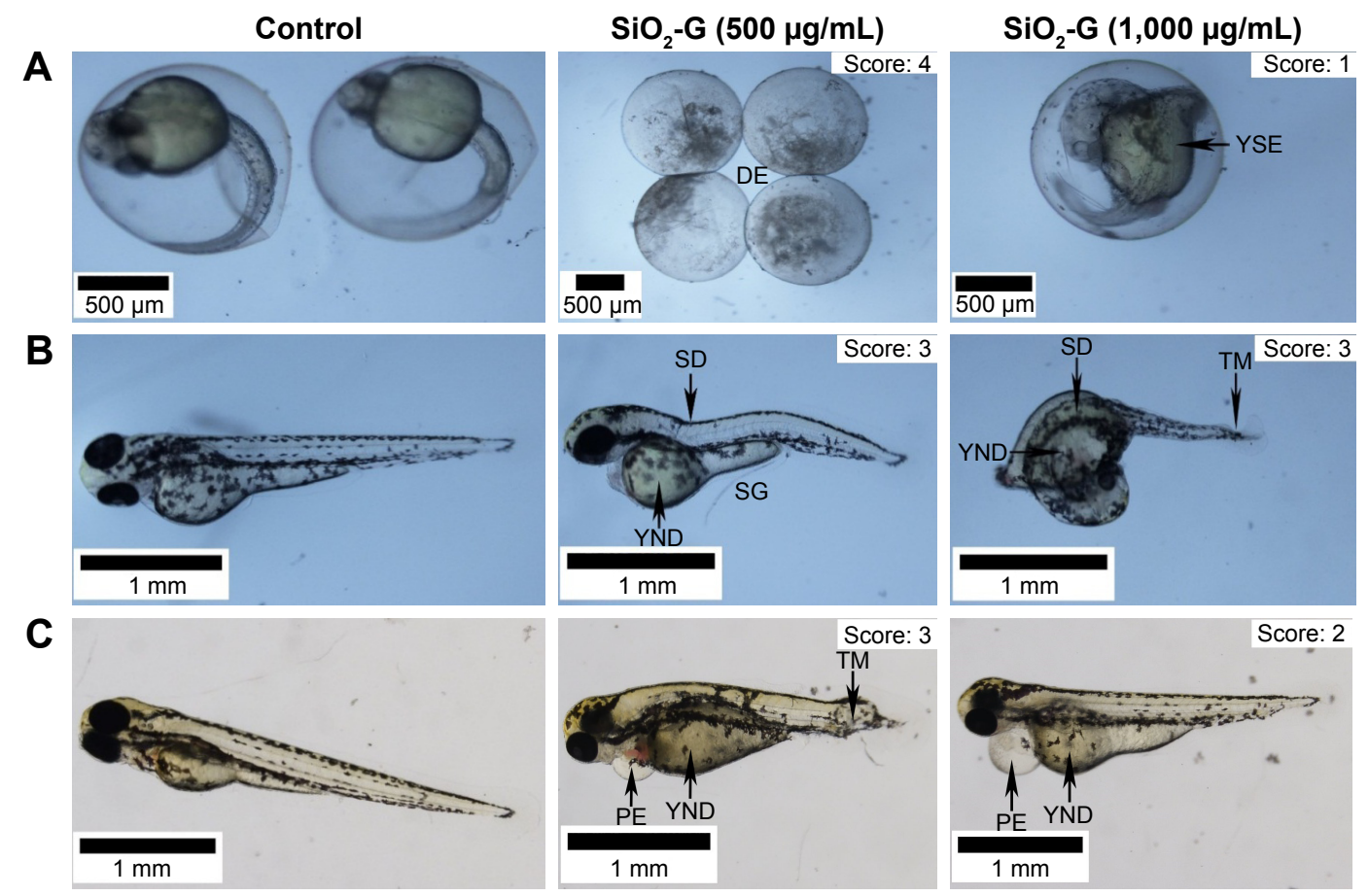

D
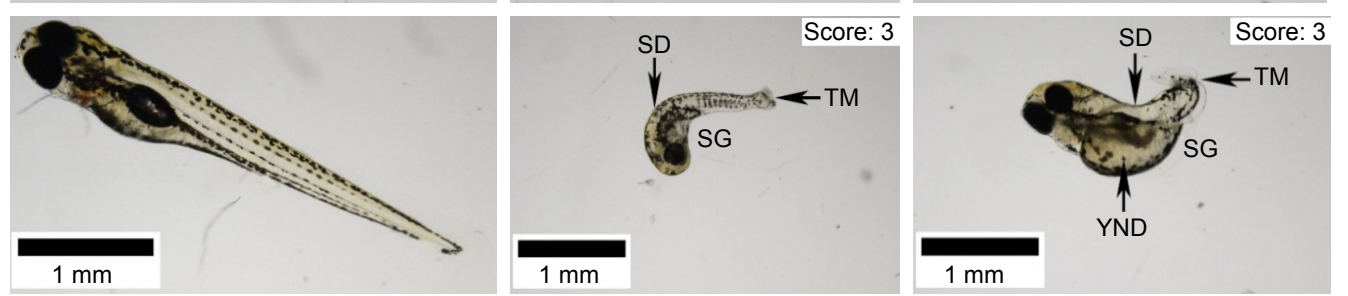

Figure 7 Malformations of zebrafish embryos/larvae.

Notes: Microscopic images ( 3 X objective) of different developmental stages of zebrafish embryos/larvae $24 \mathrm{hpf}(\mathbf{A}), 48 \mathrm{hpf}$ (B), $72 \mathrm{hpf}(\mathbf{C})$, and $96 \mathrm{hpf}$ (D). The control group presents the normal development of the embryos/larvae with no malformations (score: 0 ). The embryos treated with the $\mathrm{SiO}_{2}-\mathrm{G}$ nanohybrids $(500$ and I,000 $\mu \mathrm{g} / \mathrm{mL})$ show a range of malformations, such as YSE or YND, SD, SG, TM, and PE. The severity of malformations is scored (I-4). The highest score, 4, is marked for the DE.

Abbreviations: DE, degenerated embryos; PE, pericardial edema; SD, spinal deformity; SG, stunted growth; $\mathrm{SiO}_{2}-\mathrm{G}$, silica-gentamicin; TM, tail malformation; YND, yolk not depleted; YSE, yolk sac edema.

1, 2, and 3, respectively. In contrast, the higher exposure concentration $(1,000 \mu \mathrm{g} / \mathrm{mL})$ showed average cumulative scores of $28 \pm 9.6,27.4 \pm 15.9$, and $12 \pm 8.4$ for scores 1,2 , and 3 , respectively. These data suggest the preeminence of scores 3 and 1 as average cumulative toxicity profiles for the lower $(500 \mu \mathrm{g} / \mathrm{mL})$ and higher $(1,000 \mu \mathrm{g} / \mathrm{mL})$ exposure concentrations, respectively.

Frequencies of malformations induced by the exposure to both concentrations tested were generally similar (Figure 8). On the contrary, the frequency of malformations induced by the $\mathrm{SiO}_{2}-\mathrm{G}$ nanohybrids $24 \mathrm{hpf}$ was noticeable when compared with the control group $(4 \% \pm 0.4 \%$ at the concentration of $1,000 \mu \mathrm{g} / \mathrm{mL}$ vs $0 \%$ for the control group). This difference reached a statistical significance $(P=0.04)$ and reflected, to some extent, the recorded higher mortality rates induced by this concentration at the embryonic developmental stage of $24 \mathrm{hpf}$. The most common sublethal malformations
(Figure S8) developed by zebrafish embryos/larvae exposed to the $\mathrm{SiO}_{2}$-G nanohybrids were YSE or YND $(30.6 \% \pm 27.5 \%)$ followed by TM or BT (29.2\% $\pm 5.9 \%)$ for the lower exposure concentration $(500 \mu \mathrm{g} / \mathrm{mL})$. YSE or YND $(34.1 \% \pm 30.5 \%)$ followed by SD $(23 \% \pm 14.7 \%)$ were the most common malformations recorded for the higher exposure concentration $(1,000 \mu \mathrm{g} / \mathrm{mL})$ of the $\mathrm{SiO}_{2}-\mathrm{G}$ nanohybrids. Taken together, the present results suggest that YSE or YND, TM or BT, and $\mathrm{SD}$ are the common malformations developed by the embryos/larvae at the exposure to the $\mathrm{SiO}_{2}-\mathrm{G}$ nanohybrids. However, the overall incidences of these common malformations (Figure S8) were not significantly different from those in the control group for either exposure concentrations.

The present study has, for the first time, addressed the crucial questions of the in vivo toxicity of the $\mathrm{SiO}_{2}-\mathrm{G}$ nanohybrids using zebrafish embryos, to enable their safe and robust orthopedic applications. Prior studies have noted 


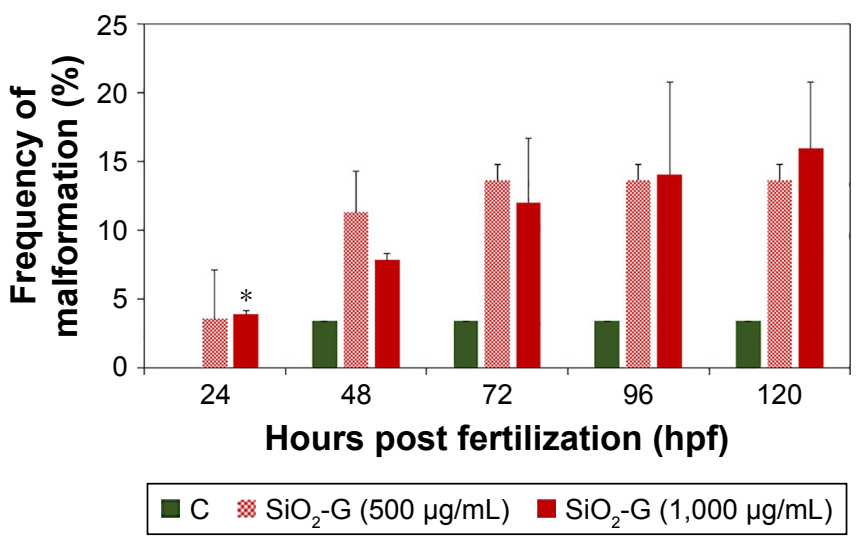

Figure 8 Frequencies of malformations of zebrafish embryos/larvae.

Notes: $\mathrm{SiO}_{2}-\mathrm{G}$ nanohybrids ( 500 and I,000 $\mu \mathrm{g} / \mathrm{mL}$ ) induced frequencies of malformations at different developmental stages. The error bars represent the standard errors of the means of two separate experiments, using 30 embryos in each group. $* P<0.05$ is significant compared with the control group using Student's $t$-test (two-tailed, unequal variance).

Abbreviations: $\mathrm{SiO}_{2}-\mathrm{G}$, silica-gentamicin; C, control group.

the importance of the size of NPs in the toxicity elicited in zebrafish embryos; for example, smaller Ag NPs have induced more in vivo toxicity. ${ }^{71-73}$ When considering the role of the size of NPs in the in vivo toxicity, the chorionic pores of the embryos should also merit attention. Lee et $\mathrm{al}^{74}$ have shown the passive diffusion of Ag NPs (30-72 nm) through the chorionic pore canals $(0.5-0.7 \mu \mathrm{m})$ of the embryos and the clogging of the pores by the aggregation of $\mathrm{Ag}$ NPs. As far as $\mathrm{SiO}_{2}$ toxicity is concerned, Duan et al ${ }^{46}$ have reported a dose- and time-dependent increase in the mortality and hatching rates of zebrafish embryos treated by $\mathrm{SiO}_{2} \mathrm{NPs}(62 \mathrm{~nm})$. More specifically, the in vitro toxicity of $\mathrm{SiO}_{2}-\mathrm{G}$ nanohybrids $(719 \pm 128 \mathrm{~nm})$ has been identified in our earlier study, ${ }^{39}$ showing a significant time-dependent decrease in the viability of human osteoblast-like SaOS-2 cells. Only $25 \% \pm 1 \%$ of cells are viable after 5 days at the nanohybrid concentration of $250 \mu \mathrm{g} / \mathrm{mL}$. This cell viability indicates severe cytotoxicity of the $\mathrm{SiO}_{2}$-G nanohybrids at the concentration of $250 \mu \mathrm{g} / \mathrm{mL}$. The present results, in contrast, show a nonsignificant increase in the mortality rates ( $120 \mathrm{hpf})$ at both exposure concentrations of the $\mathrm{SiO}_{2}$-G nanohybrids (500 and $1,000 \mu \mathrm{g} / \mathrm{mL}$ ) tested and the foremost increase in the mortality rates recorded $24 \mathrm{hpf}$, with almost no timedependent increase in the mortalities of the treated embryos/ larvae. Furthermore, all the embryos exposed to the $\mathrm{SiO}_{2}-\mathrm{G}$ nanohybrids (500 and $1,000 \mu \mathrm{g} / \mathrm{mL}$ ) hatched normally (48 hpf) and only showed a slight nonsignificant increase in the cardiac rates. These contradictory findings between our previous in vitro studies ${ }^{39}$ and the present in vivo investigations obtained even using the same synthesis strategy of the $\mathrm{SiO}_{2}-\mathrm{G}$ nanohybrids are apparently attributed to the size of the $\mathrm{SiO}_{2}-\mathrm{G}$ nanohybrids $(879 \pm 264 \mathrm{~nm})$. The chorionic pore diameter hinders the full diffusion of the large-sized nanohybrids into the embryonic tissues. The higher mortality rates recorded in the time frame around $24 \mathrm{hpf}$ in the present study resemble the findings of Lee et al, ${ }^{75}$ who defined the embryonic late segmentation stage (21-23 hpf), showing the highest mortalities as the most sensitive stage of zebrafish embryos to the toxicities induced by Ag NPs $(13.1 \pm 2.5 \mathrm{~nm})$. The embryonic hatching stage (48-50 hpf) was defined as the most resistant stage to the toxicities of Ag NPs in the same study.

Regarding the scoring spectra and the frequencies of malformations, it is somewhat surprising that the average cumulative scoring toxicity profile was higher for the lower exposure concentration, although the frequency of malformations (Figure 8) at different developmental stages was not significantly different from the control group. In contrast, the higher exposure concentration had a lower average cumulative scoring toxicity profile and a significantly different incidence of malformations (Figure 8), from the control group, recorded at $24 \mathrm{hpf}$. This significant different incidence of malformations can also correlate with the slightly higher mortality rates recorded for the higher exposure concentration only $24 \mathrm{hpf}$ and can specify a possible dose-dependent sublethal toxicity (malformations) for the nanohybrids at the exposure of the embryos to the higher exposure concentration, only $24 \mathrm{hpf}$. This dose-dependent sublethal toxicity seems to happen only at $24 \mathrm{hpf}$ because of the sensitivity of the embryos at this stage. Furthermore, the small chorionic pore diameter hindered the full diffusion of the large-sized $\mathrm{SiO}_{2}$-G nanohybrids; consequently, only the sublethal toxicity reached a significant level at this stage, while the mortality rates only increased without reaching 
significant levels even at the higher exposure concentration. Similar to the mortality rates (showing almost no timedependent increase), there was no increase in the cumulative scoring profile of all the time points at the higher exposure concentration. Thus far, the present results provide further support for the hypothesis that the late segmentation stage is the most sensitive stage to the toxicities elicited by $\mathrm{SiO}_{2}-\mathrm{G}$ nanohybrids. The crucial role of the size of the $\mathrm{SiO}_{2}-\mathrm{G}$ nanohybrids is also emphasized at the embryonic developmental stage of $24 \mathrm{hpf}$ through the nonsignificant increase in the mortality rates recorded in the exposed embryos at this stage and in the significant malformations recorded only at $24 \mathrm{hpf}$ at the higher exposure concentration.

Proceeding now to the common malformations developed by the embryos/larvae at the exposure to the $\mathrm{SiO}_{2}-\mathrm{G}$ nanohybrids, YSE or YND, TM or BT, and SD were the common malformations recorded. The present results match those observed in an earlier study, ${ }^{46}$ recording YSE and TMs as common malformations induced by $\mathrm{SiO}_{2}$ NPs. The presently demonstrated deficiency in yolk utilization can explain the SG shown in this study as it infers that the embryos were not using all the yolk nutrients required for growth. ${ }^{42,71}$ Overall, while the present study shows neither significant mortalities nor significant common malformations induced by the exposure of the embryos to the $\mathrm{SiO}_{2}-\mathrm{G}$ nanohybrids, it does point towards the pivotal role of the large size of the nanohybrids. This large size possibly causes less diffusion of the nanohybrids into the embryonic tissue, governed by the chorionic pore diameter, and consequently, decreases the elicited in vivo toxicity of the embryos exposed to the $\mathrm{SiO}_{2}-\mathrm{G}$ nanohybrids. Relating the mild or nonsignificant effects caused by the $\mathrm{SiO}_{2}-\mathrm{G}$ nanohybrids in vivo in the present study to our previously recorded significant cytotoxicity of the $\mathrm{SiO}_{2}-\mathrm{G}$ nanohybrids towards human osteoblast-like SaOS-2 cells ${ }^{39}$ adds more complexity to the safety issues in using the $\mathrm{SiO}_{2}-\mathrm{G}$ nanohybrids as an antibiotic delivery system in orthopedic applications. These discrepancies between the in vitro and in vivo levels of toxicity of the same nanomaterials are consistent with data obtained in earlier studies. These earlier data, however, have shown more toxic effects in zebrafish embryos than in mammalian cells using Ag NPs (size of $95.68 \mathrm{~nm}$ dispersed in water) ${ }^{76}$ or metal-organic frameworks (diameter of $170 \mathrm{~nm}$ ). ${ }^{77}$

In a nutshell, the present study has identified different approaches to combating the resistance of planktonic MRSA cells to gentamicin as well as for the complete eradication of preformed $E$. coli biofilms. These results highlight the possibility to use the $\mathrm{SiO}_{2}-\mathrm{G}$ nanohybrids as an antibiotic delivery system in orthopedic applications, preventing the formation of biofilms and eradicating the preformed biofilms of MRSA and $E$. coli, respectively. Even though the mortality rates of the zebrafish embryos exposed to the $\mathrm{SiO}_{2}-\mathrm{G}$ nanohybrids remained statistically nonsignificant, this addresses the two sides of the same coin: 1) the possible biocompatibility of such delivery systems in orthopedic applications, and 2) the complexities and uncertainties associated with the safety issues of such delivery systems. These uncertainties result from the difficulty to interpret the discrepancies between the results of in vivo and in vitro studies in the present and our previous work, ${ }^{39}$ respectively.

\section{Conclusion}

This work is the first empirical investigation on $\mathrm{SiO}_{2}-\mathrm{G}$ nanohybrids ( $879 \pm 264 \mathrm{~nm}$ ) using both in vitro assays (antibacterial and antibiofilm effects) and in vivo toxicity assessments in zebrafish embryos. The main in vitro findings of this work are as follows: 1) The $\mathrm{SiO}_{2}-\mathrm{G}$ nanohybrids are more effective than pristine gentamicin against planktonic MRSA and E. coli biofilms. 2) The $\mathrm{SiO}_{2}-\mathrm{G}$ nanohybrids can destroy the tenacity of planktonic MRSA cells with a minimum inhibitory and bactericidal concentration of $500 \mu \mathrm{g} / \mathrm{mL}$. 3) The $\mathrm{SiO}_{2}-\mathrm{G}$ nanohybrids can entirely eradicate $E$. coli biofilms at a MBEC of $250 \mu \mathrm{g} / \mathrm{mL}$. 4) The treatment of E. coli biofilms with $\mathrm{SiO}_{2}-\mathrm{G}$ nanohybrids causes an utter ultrastructural deformation of $E$. coli cells, showing deformed cell shapes and wrinkled cell walls, as demonstrated by SEM. The main in vivo findings of this work are as follows: 1) $24 \mathrm{hpf}$ is the most sensitive embryonic developmental stage to the toxicity of $\mathrm{SiO}_{2}-\mathrm{G}$ nanohybrids. 2) Even though only a nonsignificant increase in mortalities is detected in the exposed embryos $24 \mathrm{hpf}$, malformations with significantly different frequency from the control group are also detected $24 \mathrm{hpf}$ for the higher exposure concentration. 3) The large size of $\mathrm{SiO}_{2}-\mathrm{G}$ nanohybrids apparently plays a pivotal role in the nonsignificant occurrence of mortalities recorded in zebrafish embryos. 4) Nondepleted yolk and SG types of malformations are the most common ones developed by zebrafish embryos/larvae, indicating the nonusage of the required nutrients in the yolk after exposure to the $\mathrm{SiO}_{2}-\mathrm{G}$ nanohybrids. Therefore, this work provides robust evidence for the use of the $\mathrm{SiO}_{2}-\mathrm{G}$ nanohybrids as biocompatible antibiotic delivery systems combating recalcitrant planktonic MRSA cells and preventing and eradicating MRSA and E. coli biofilms. However, more studies are needed to elucidate the in vivo toxic effects of smaller sized $\mathrm{SiO}_{2}-\mathrm{G}$ nanohybrids to conclusively demonstrate the possibility of safely using such delivery systems. Continued efforts to reveal the underlying mechanisms of 
action of the $\mathrm{SiO}_{2}-\mathrm{G}$ nanohybrids are also needed to decipher the basis for the better antibacterial and antibiofilm effects of the nanohybrids than pristine gentamicin.

\section{Acknowledgments}

DAM gratefully thanks Alfred Kordelin Foundation for the personal working grant [grant number 170297] for this $\mathrm{PhD}$ thesis work and School of Chemical Engineering, Aalto University, for the funding support. The authors kindly thank the Electron Microscopy Unit, Institute of Biotechnology, University of Helsinki, for further processing the fixed biofilms formed on the pegs of the CBD for SEM analyses. The authors also express their heartfelt gratitude to Prof Anming Meng and Dr Shunji Jia for kindly providing the zebrafish embryos and allowing DAM to use the facilities of the State Key Laboratory of Biomembrane and Membrane Biotechnology, Department of Biological Sciences and Biotechnology, Tsinghua University. They acknowledge the provision of facilities and technical support by Aalto University at OtaNano Nanomicroscopy Center (Aalto-NMC).

\section{Author contributions}

DAM defined the research plan under the supervision of $\mathrm{S}-\mathrm{PH}, \mathrm{KN}$, and QF. DAM prepared the nanomaterials under the supervision of S-PH (in Aalto University) and QF (in Tsinghua University). DAM characterized the nanomaterials by SEM, zeta potential analyses, and TEM under the supervision of MBL (in Aalto University) and QF (in Tsinghua University). DAM and UH designed the antibacterial and antibiofilm tests under the supervision of KN (in Aalto University) and AP (in University of Helsinki). DAM performed all the antibacterial and antibiofilm tests at the University of Helsinki. DAM analyzed the fixed biofilms formed on the pegs of the CBD by SEM under the supervision of MBL at Aalto University. PM took part in the SEM analyses. DAM and WH designed the in vivo toxicity experiments under the supervision of QF. DAM performed all the in vivo toxicity experiments in Tsinghua University. YM took part in the microscopic analyses of the zebrafish embryos. DAM interpreted all the characterization results, antibacterial and antibiofilm results, SEM analyses of biofilms, and the in vivo toxicity results under the supervision of Prof MBL. DAM wrote the manuscript under the supervision of MBL. All the authors revised the manuscript with merited contributions endowed by UH. All the authors approved the final version of the manuscript. All authors contributed toward data analysis, drafting and revising the paper and agree to be accountable for all aspects of the work.

\section{Disclosure}

The authors report no conflicts of interest in this work.

\section{References}

1. Li B, Webster TJ. Bacteria antibiotic resistance: new challenges and opportunities for implant-associated orthopedic infections. J Orthop Res. 2018;36(1):22-32.

2. McCarthy H, Rudkin JK, Black NS, Gallagher L, O’Neill E, O'Gara JP. Methicillin resistance and the biofilm phenotype in Staphylococcus aureus. Front Cell Infect Microbiol. 2015;5:1-9.

3. Simovic S, Ghouchi-Eskandar N, Sinn AM, Losic D, Prestidge CA. Silica materials in drug delivery applications. Curr Drug Discov Technol. 2011;8(3):269-276.

4. Tong SY, Davis JS, Eichenberger E, Holland TL, Fowler VG Jr. Staphylococcus aureus infections: epidemiology, pathophysiology, clinical manifestations, and management. Clin Microbiol Rev. 2015; 28(3):603-661.

5. Costerton JW, Stewart PS, Greenberg EP. Bacterial biofilms: a common cause of persistent infections. Science. 1999;284(5418):1318-1322.

6. Mah TF, O'Toole GA. Mechanisms of biofilm resistance to antimicrobial agents. Trends Microbiol. 2001;9(1):34-39.

7. Stewart PS, Costerton JW. Antibiotic resistance of bacteria in biofilms Lancet. 2001;358(9276):135-138.

8. Van Houdt R, Michiels CW. Role of bacterial cell surface structures in Escherichia coli biofilm formation. Res Microbiol. 2005;156(5-6): 626-633.

9. Lewis K. Riddle of biofilm resistance. Antimicrob Agents Chemother. 2001;45(4):999-1007.

10. Brown MR, Allison DG, Gilbert P. Resistance of bacterial biofilms to antibiotics: a growth-rate related effect? J Antimicrob Chemother 1988;22(6):777-780.

11. Anwar H, Strap JL, Costerton JW. Establishment of aging biofilms: possible mechanism of bacterial resistance to antimicrobial therapy Antimicrob Agents Chemother. 1992;36(7):1347-1351.

12. Williams I, Venables WA, Lloyd D, Paul F, Critchley I. The effects of adherence to silicone surfaces on antibiotic susceptibility in Staphylococcus aureus. Microbiology. 1997;143(Pt 7):2407-2413.

13. Smith AW. Biofilms and antibiotic therapy: is there a role for combating bacterial resistance by the use of novel drug delivery systems? Adv Drug Deliv Rev. 2005;57(10):1539-1550.

14. Das JR, Bhakoo M, Jones MV, Gilbert P. Changes in the biocide susceptibility of Staphylococcus epidermidis and Escherichia coli cells associated with rapid attachment to plastic surfaces. J Appl Microbiol. 1998;84(5):852-858.

15. Anwar H, van Biesen T, Dasgupta M, Lam K, Costerton JW. Interaction of biofilm bacteria with antibiotics in a novel in vitro chemostat system. Antimicrob Agents Chemother. 1989;33(10):1824-1826.

16. Toté K, Horemans T, Berghe DV, Maes L, Cos, P. Inhibitory effect of biocides on the viable masses and matrices of Staphylococcus aureus and Pseudomonas aeruginosa Biofilms. Appl Environ Microbiol. 2010;76(10):3135-3142.

17. Allan ND, Omar A, Harding MW, Olson ME. A rapid, high-throughput method for culturing, characterizing and biocide efficacy testing of both planktonic cells and biofilms. Science against microbial pathogens: Communicating current research and technological advances. Edition: Microbiology Book Series. Mendez-Vilas A. Badajoz, Spain: Formatex Research Center; 2011:864-871.

18. Choi O, Yu CP, Esteban Fernández G, Hu Z, Hu Z, Ferna GE. Interactions of nanosilver with Escherichia coli cells in planktonic and biofilm cultures. Water Res. 2010;44(20):6095-6103.

19. van de Belt H, Neut D, van Horn JR, van der Mei HC, Schenk W, Busscher HJ. Antibiotic resistance - to treat or not to treat? Nat Med. 1999;5(4):358-359.

20. Kankala RK, Liu C-G, Chen A-Z, et al. Overcoming multidrug resistance through the synergistic effects of hierarchical $\mathrm{pH}$-sensitive, ROS-generating nanoreactors. ACS Biomater Sci Eng. 2017;3(10):2431-2442. 
21. Kuthati $Y$, Kankala RK, Busa P, et al. Phototherapeutic spectrum expansion through synergistic effect of mesoporous silica trio-nanohybrids against antibiotic-resistant gram-negative bacterium. $J$ Photochem Photobiol B. 2017;169:124-133.

22. El-Ghannam A, Ahmed K, Omran M. Nanoporous delivery system to treat osteomyelitis and regenerate bone: gentamicin release kinetics and bactericidal effect. J Biomed Mater Res B Appl Biomater. 2005;73(2): 277-284.

23. Seleem MN, Munusamy P, Ranjan A, Alqublan H, Pickrell G, Sriranganathan N. Silica-antibiotic hybrid nanoparticles for targeting intracellular pathogens. Antimicrob Agents Chemother. 2009;53(10): 4270-4274.

24. Shi X, Wang Y, Ren L, Zhao N, Gong Y, Wang DA. Novel mesoporous silica-based antibiotic releasing scaffold for bone repair. Acta Biomater. 2009;5(5):1697-1707.

25. Xue JM, Shi M. PLGA/mesoporous silica hybrid structure for controlled drug release. J Control Release. 2004;98(2):209-217.

26. Xue JM, Tan CH, Lukito D. Biodegradable polymer-silica xerogel composite microspheres for controlled release of gentamicin. J Biomed Mater Res B Appl Biomater. 2006;78(2):417-422.

27. Mosselhy DA, Ge Y, Gasik M, Nordström K, Natri O, Hannula SP. Silica-gentamicin nanohybrids: synthesis and antimicrobial action. Materials (Basel). 2016;9(3):170.

28. Aughenbaugh W, Radin S, Ducheyne P. Silica sol-gel for the controlled release of antibiotics. II. The effect of synthesis parameters on the in vitro release kinetics of vanomycin. J Biomed Mater Res. 2001;57(3): 321-326.

29. Radin S, Ducheyne P, Kamplain T, Tan BH. Silica sol-gel for the controlled release of antibiotics. I. Synthesis, characterization, and in vitro release. J Biomed Mater Res. 2001;57(2):313-320.

30. Agnihotri S, Pathak R, Jha D, et al. Synthesis and antimicrobial activity of aminoglycoside-conjugated silica nanoparticles against clinical and resistant bacteria. New J Chem. 2015;39(9):6746-6755.

31. Kovalenko Y, Sotiri I, Timonen JVI, et al. Bacterial interactions with immobilized liquid layers. Adv Healthc Mater. 2017;6(15): 1600948.

32. Arciola CR, An YH, Campoccia D, Donati ME, Montanaro L. Etiology of implant orthopedic infections: a survey on 1027 clinical isolates. Int J Artif Organs. 2005;28(11):1091-1100.

33. Meng H, Xia T, George S, Nel AE. A predictive toxicological paradigm for the safety assessment of nanomaterials. ACS Nano. 2009;3(7): $1620-1627$.

34. Liu X, Sui B, Sun J. Blood-brain barrier dysfunction induced by silica NPs in vitro and in vivo: involvement of oxidative stress and Rho-kinase/ JNK signaling pathways. Biomaterials. 2017;121:64-82.

35. Orlando A, Cazzaniga E, Tringali M, et al. Mesoporous silica nanoparticles trigger mitophagy in endothelial cells and perturb neuronal network activity in a size- and time-dependent manner. Int $J$ Nanomedicine. 2017;12:3547-3559.

36. Chou CC, Chen W, Hung Y, Mou CY. Molecular elucidation of biological response to mesoporous silica nanoparticles in vitro and in vivo. ACS Appl Mater Interfaces. 2017;9(27):22235-22251.

37. Yang X, Liu X, Li Y, et al. The negative effect of silica nanoparticles on adipogenic differentiation of human mesenchymal stem cells. Mater Sci Eng C Mater Biol Appl. 2017;81:341-348.

38. Ha SW, Sikorski JA, Weitzmann MN, Beck GR Jr. Bio-active engineered $50 \mathrm{~nm}$ silica nanoparticles with bone anabolic activity: therapeutic index, effective concentration, and cytotoxicity profile in vitro. Toxicol In vitro. 2014;28(3):354-364.

39. He W, Mosselhy DA, Zheng Y, et al. Effects of silica-gentamicin nanohybrids on osteogenic differentiation of human osteoblast-like SaOS-2 cells. Int J Nanomedicine. 2018;13:877-893.

40. Thomas CR, George S, Horst AM, et al. Nanomaterials in the environment: from materials to high-throughput screening to organisms. ACS Nano. 2011;5(1):13-20.

41. Bugel SM, Tanguay RL, Planchart A. Zebrafish: a marvel of highthroughput biology for 21st century toxicology. Curr Environ Health Rep. 2014;1(4):341-352.
42. Sant KE, Timme-Laragy AR. Zebrafish as a model for toxicological perturbation of yolk and nutrition in the early embryo. Curr Environ Health Rep. 2018;5(1):125-133.

43. Spoorendonk KM, Hammond CL, Huitema LFA, Vanoevelen J, Schulte-Merker S. Zebrafish as a unique model system in bone research: the power of genetics and in vivo imaging. J Appl Ichthyology. 2010; 26(2):219-224

44. Renn J, Winkler C, Schartl M, Fischer R, Goerlich R. Zebrafish and medaka as models for bone research including implications regarding space-related issues. Protoplasma. 2006;229(2-4):209-214.

45. Zhenhua L, Deepa A, Inleng C, Mingyuen LS. The zebrafish: a novel model organism for bone research. Pharmacol Clin Chinese Mater Medica. 2010;3:029.

46. Duan J, Yu Y, Shi H, et al. Toxic effects of silica nanoparticles on zebrafish embryos and larvae. PLoS One. 2013;8(9):e74606.

47. Sharif F, Porta F, Meijer AH, Kros A, Richardson MK. Mesoporous silica nanoparticles as a compound delivery system in zebrafish embryos. Int J Nanomedicine. 2012;7:1875-1890.

48. Corrêa GG, Morais EC, Brambilla R, et al. Effects of the sol-gel route on the structural characteristics and antibacterial activity of silica-encapsulated gentamicin. Colloids Surf B Biointerfaces. 2014;116: 510-517.

49. CLSI. M02-A12 Performance Standards for Antimicrobial Disk Susceptibility Tests; Approved Standard. 12th ed. Wayne, PA: Clinical and Laboratory Standards Institute; 2015.

50. CLSI. M100 Performance Standards for Antimicrobial Susceptibility Testing. 27th ed. Wayne, PA: Clinical and Laboratory Standards Institute; 2017

51. CLSI. M07-A10: Methods for Dilution Antimicrobial Susceptibility Tests for Bacteria That Grow Aerobically; Approved Standard. 10th ed. Wayne, PA: Clinical and Laboratory Standards Institute; 2015.

52. CLSI. M26-A: Methods for Determining Bactericidal Activity of Antimicrobial Agents; Approved Guideline. Wayne, PA: Clinical and Laboratory Standards Institute; 1999.

53. Harrison JJ, Ceri H, Yerly J, et al. The use of microscopy and threedimensional visualization to evaluate the structure of microbial biofilms cultivated in the Calgary Biofilm Device. Biol Proced Online. 2006; 8(1):194-215.

54. Kimmel CB, Ballard WW, Kimmel SR, Ullmann B, Schilling TF. Stages of embryonic development of the zebrafish. Dev Dyn. 1995;203(3): 253-310.

55. Heiden TC, Dengler E, Kao WJ, Heideman W, Peterson RE. Developmental toxicity of low generation PAMAM dendrimers in zebrafish. Toxicol Appl Pharmacol. 2007;225(1):70-79.

56. van de Belt H, Neut D, Uges DR, et al. Surface roughness, porosity and wettability of gentamicin-loaded bone cements and their antibiotic release. Biomaterials. 2000;21(19):1981-1987.

57. van de Belt H, Neut D, Schenk W, van Horn JR, van Der Mei HC, Busscher HJ. Staphylococcus aureus biofilm formation on different gentamicin-loaded polymethylmethacrylate bone cements. Biomaterials. 2001;22(12):1607-1611.

58. Stallmann HP, Faber C, Bronckers AL, Nieuw Amerongen AV, Wuisman PI. In vitro gentamicin release from commercially available calcium-phosphate bone substitutes influence of carrier type on duration of the release profile. BMC Musculoskelet Disord. 2006;7:18.

59. Mebert AM, Aimé C, Alvarez GS, et al. Silica core-shell particles for the dual delivery of gentamicin and rifamycin antibiotics. $J$ Mater Chem B. 2016;4:3135-3144.

60. Alvarez GS, Hélary C, Mebert AM, Wang X, Coradin T, Desimone MF. Antibiotic-loaded silica nanoparticle-collagen composite hydrogels with prolonged antimicrobial activity for wound infection prevention. J Mater Chem B. 2014;2:4660-4670.

61. Hu J, Zhang N Jr, Li L, et al. The synergistic bactericidal effect of vancomycin on UTMD treated biofilm involves damage to bacterial cells and enhancement of metabolic activities. Sci Rep. 2018;8(1):192.

62. Rediske AM, Roeder BL, Nelson JL, et al. Pulsed ultrasound enhances the killing of Escherichia coli biofilms by aminoglycoside antibiotics in vivo. Antimicrob Agents Chemother. 2000;44(3):771-772. 
63. van de Belt H, Neut D, Schenk W, van Horn JR, van der Mei HC, Busscher HJ. Gentamicin release from polymethylmethacrylate bone cements and Staphylococcus aureus biofilm formation. Acta Orthop Scand. 2000;71(6):625-629.

64. Zhang A, Mu H, Zhang W, Cui G, Zhu J, Duan J. Chitosan coupling makes microbial biofilms susceptible to antibiotics. Sci Rep. 2013;3(1):3364.

65. Ceri H, Olson ME, Stremick C, Read RR, Morck D, Buret A. The Calgary Biofilm Device: new technology for rapid determination of antibiotic susceptibilities of bacterial biofilms. J Clin Microbiol. 1999; 37(6):1771-1776.

66. Abdelghany SM, Quinn DJ, Ingram RJ, et al. Gentamicin-loaded nanoparticles show improved antimicrobial effects towards Pseudomonas aeruginosa infection. Int J Nanomedicine. 2012;7:4053-4063.

67. Hou Y, Wang Z, Zhang P, et al. Lysozyme associated liposomal gentamicin inhibits bacterial biofilm. Int J Mol Sci. 2017;18(4):784.

68. Shigeta M, Tanaka G, Komatsuzawa H, Sugai M, Suginaka H, Usui T. Permeation of antimicrobial agents through Pseudomonas aeruginosa biofilms: a simple method. Chemotherapy. 1997;43(5):340-345.

69. Ishida H, Ishida Y, Kurosaka Y, Otani T, Sato K, Kobayashi H. In vitro and in vivo activities of levofloxacin against biofilm-producing Pseudomonas aeruginosa. Antimicrob Agents Chemother. 1998;42(7):1641-1645.

70. Duncan B, Li X, Landis RF, et al. Nanoparticle-stabilized capsules for the treatment of bacterial biofilms. ACS Nano. 2015;9(8):7775-7782.
71. Bar-Ilan O, Albrecht RM, Fako VE, Furgeson DY. Toxicity assessments of multisized gold and silver nanoparticles in zebrafish embryos. Small. 2009;5(16):1897-1910.

72. Kim KT, Truong L, Wehmas L, Tanguay RL. Silver nanoparticle toxicity in the embryonic zebrafish is governed by particle dispersion and ionic environment. Nanotechnology. 2013;24(11):115101.

73. Mosselhy DA, He W, Li D, Meng Y, Feng Q. Silver nanoparticles: in vivo toxicity in zebrafish embryos and a comparison to silver nitrate. J Nanopart Res. 2016;18(8):1-15.

74. Lee KJ, Browning LM, Nallathamby PD, Desai T, Cherukuri PK, $\mathrm{Xu} \mathrm{XH}$. In vivo quantitative study of sized-dependent transport and toxicity of single silver nanoparticles using zebrafish embryos. Chem Res Toxicol. 2012;25(5):1029-1046.

75. Lee KJ, Browning LM, Nallathamby PD, Osgood CJ, Xu XHN. Silver nanoparticles induce developmental stage-specific embryonic phenotypes in zebrafish. Nanoscale. 2013;5(23):11625-11636.

76. George S, Xia T, Rallo R, et al. Use of a high-throughput screening approach coupled with in vivo zebrafish embryo screening to develop hazard ranking for engineered nanomaterials. ACS Nano. 2011;5(3): 1805-1817.

77. Ruyra À, Yazdi A, Espín J, et al. Synthesis, culture medium stability, and in vitro and in vivo zebrafish embryo toxicity of metal-organic framework nanoparticles. Chemistry. 2015;21(6):2508-2518.
International Journal of Nanomedicine

\section{Publish your work in this journal}

The International Journal of Nanomedicine is an international, peerreviewed journal focusing on the application of nanotechnology in diagnostics, therapeutics, and drug delivery systems throughout the biomedical field. This journal is indexed on PubMed Central, MedLine, CAS, SciSearch $®$, Current Contents $\AA /$ Clinical Medicine,

\section{Dovepress}

Journal Citation Reports/Science Edition, EMBase, Scopus and the Elsevier Bibliographic databases. The manuscript management system is completely online and includes a very quick and fair peer-review system, which is all easy to use. Visit http://www.dovepress.com/ testimonials.php to read real quotes from published authors. 